NBSIR 82-2553

\title{
Development of Interim Performance Criteria for Restoration Coatings for Porcelain Enamel Surfaces
}

U.S. DEPARTMENT OF COMMERCE

National Bureau of Standards National Engineering Laboratory Center for Building Technology Building Materials Division Washington, DC 20234

June 1982

Prepared for

Division of Energy, Building Technology and Standards Department of Housing and Urban Development 


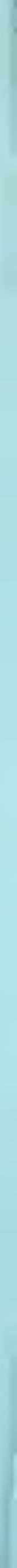


DEVELOPMENT OF INTERIM

PERFORMANCE CRITERIA FOR

RESTORATION COATINGS FOR PORCELAIN

ENAMEL SURFACES

James F. Seiler

Paul G. Campbell

U.S. DEPARTMENT OF COMMERCE

National Bureau of Standards

National Engineering Laboratory

Center for Building Technology

Building Materials Division

Washington, DC 20234

June 1982

Prepared for

Division of Energy, Building Technology and Standards

Department of Housing and Urban Development

Washington, DC 20410

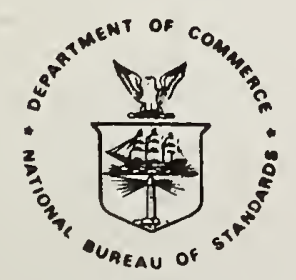

U.S. DEPARTMENT OF COMMERCE, Malcolm Baldrige, Secretary NATIONAL BUREAU OF STANDARDS, Ernest Ambler, Director 



\section{ABSTKACT}

A study was performed to develop interim performance criteria for restoration coatings for porcelain enamel surfaces. The laboratory study consisted of evaluating five restoration coatings which had been applied to porcelain enamel test panels with various surface conditions. Performance characteristics of the coatings examined included appearance, adhesion, impact resistance, stain resistance and fungal resistance. Existing test methods were used in the study if appropriate methods were available. However, the laboratory studies led to the development of a new cyclic exposure test and the use of a newly developed method for measuring adhesion. Adhesion of the coatings was the performance characteristic most sensitive to change with time of exposure to the newly developed cyclic exposure test. Interim performance criteria for restoration coatings for porcelain enamel surfaces were developed, based upon the results of the laboratory study.

Additional studies are being conducted to assess the performance and durability of selected restoration coatings applied to bath tubs in public housing units. Since the field studies are not yet completed, they are not addressed in this report. 


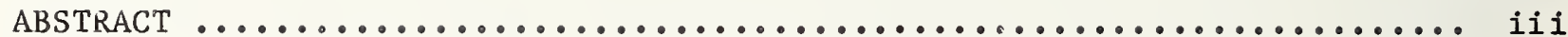

LIST OF TABLES $\ldots \ldots \ldots \ldots \ldots \ldots \ldots \ldots \ldots \ldots \ldots \ldots \ldots \ldots \ldots \ldots \ldots \ldots \ldots \ldots \ldots \ldots \ldots$ v

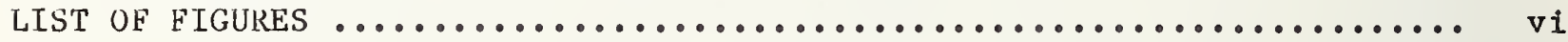

1. INTRODUCTION $\ldots \ldots \ldots \ldots \ldots \ldots \ldots \ldots \ldots \ldots \ldots \ldots \ldots \ldots \ldots \ldots \ldots \ldots \ldots \ldots \ldots \ldots \ldots$

1.1 Background $\ldots \ldots \ldots \ldots \ldots \ldots \ldots \ldots \ldots \ldots \ldots \ldots \ldots \ldots \ldots \ldots \ldots \ldots \ldots \ldots$

1.2 objective $\ldots \ldots \ldots \ldots \ldots \ldots \ldots \ldots \ldots \ldots \ldots \ldots \ldots \ldots \ldots \ldots \ldots \ldots \ldots \ldots \ldots \ldots$

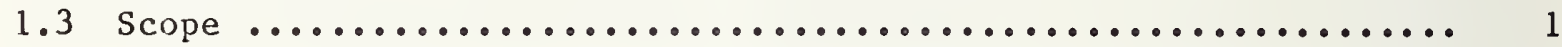

2. IDENTIFICATION OF COMMERCIALLY AVAILABLE RESTORATION COATINGS ...... 2

3. PERFORMANCE REQUTREMENTS .............................. 3

4. LABORATORY EVALUATIONS ................................ 4

4.1 Materials $\ldots \ldots \ldots \ldots \ldots \ldots \ldots \ldots \ldots \ldots \ldots \ldots \ldots \ldots \ldots \ldots \ldots \ldots \ldots \ldots \ldots$

4.1.1 Treatment of Test Panels Prior to Restoration ......... 4

4.l.2 Restoration Coatings .......................... 5

4.2 Test Methods ................................. 5

4.2.1 Accelerated Bathtub Exposure .................... 5 5

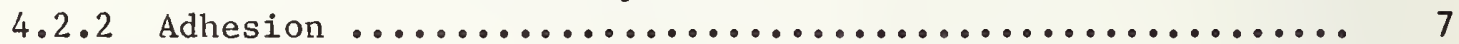

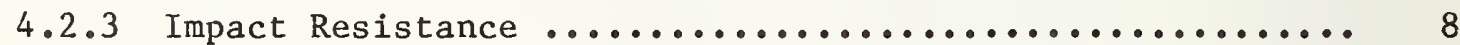

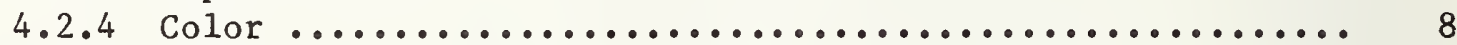

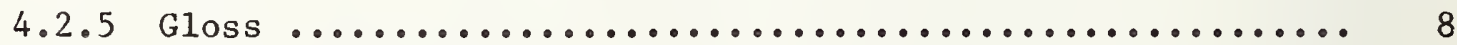

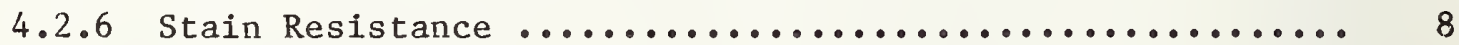

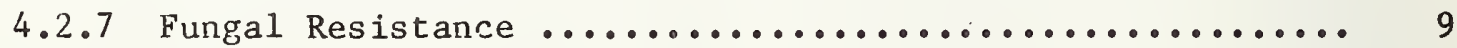

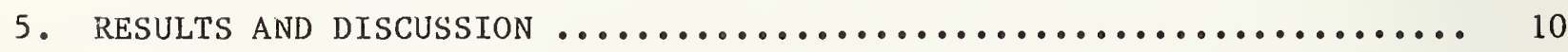

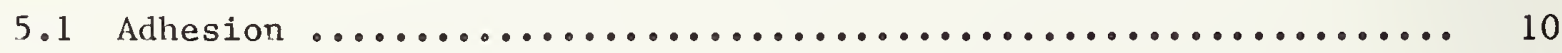

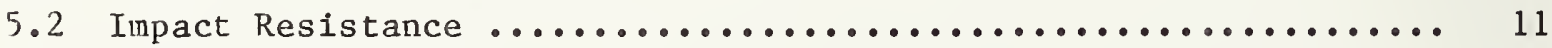

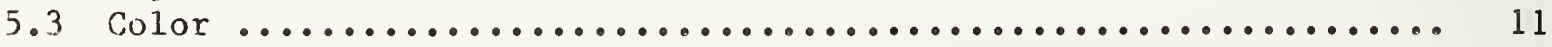

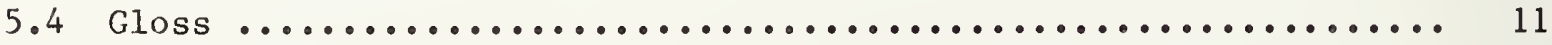

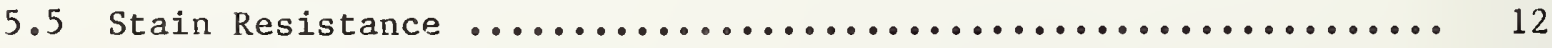

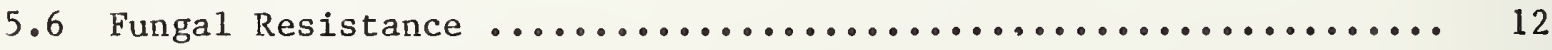

6. INTERI PERFORTANCE CRITERIA .......................... 13

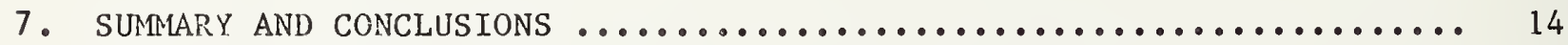

8. FUTURE RESEARCH ....................................... 15

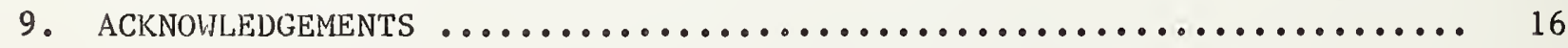

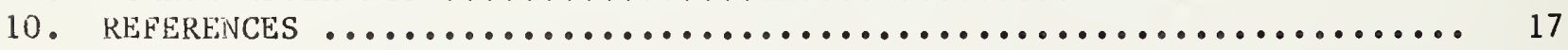

APPEINDIX A - COMMERCIALLY AVAILABLE RESTORATION COATINGS ............ A-1

APPENDIX B - INTERIM PERFORMANCE CRITERIA FOR RESTORATION COATINGS FOR PORCELAIN ENAMEL SURFACES ........................ B-1 


\section{LIST OF TABLES}

Page

Table 1. Average Impact Resistance of Restoration Coatings, Surface

Table 2. Color Differences of Restoration Coatings, Surface Condition 1, After ABECs ........................... 18

Table 3. Color Differences of Restoration Coatings, Surface Conditions 2,3 , and 4 , After 25 ABECs ......................... 19

Table 4. $60^{\circ}$ Gloss of Restoration Coatings, Surface Condition 1, After

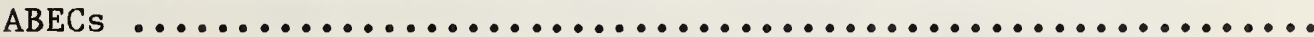

Table 5. $60^{\circ}$ Gloss of Restoration Coatings, Surface Conditions 2, 3,

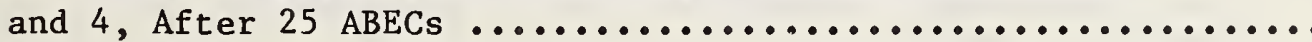

Table 6. Stain Resistance of Restoration Coatings Using Three 


\section{LIST OF FIGURES}

Page

Figure 1. Pattern for preconditioning test panels ................

Figure 2. Circuit diagram for recycling controls on modified

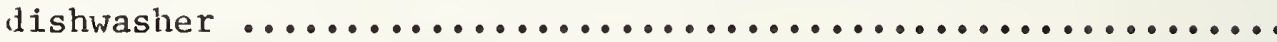

Figure 3. Recycling controls on modified dishwasher .............. 24

Figure 4. Accelerated bath cycle apparatus - overall view .......... 24

Eigure 5. Accelerated bath cycle apparatus - machine unloaded ........ 25

Figure 6. Accelerated bath cycle apparatus - panels loaded in rack ....

Eigure 7. Modified abrasion procedure using P.E.I. abrasion tester

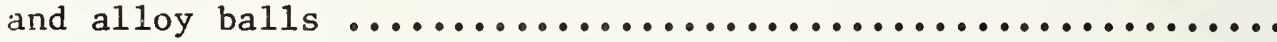

Figure 8. Modified abrasion procedure - placing test panels on

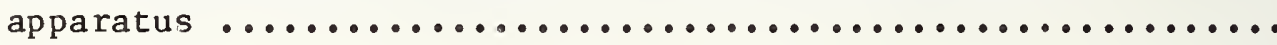

Figure 9. Modified abrasion procedure - placing containers for holding alloys balls and abrasive on test panels ..........

Figure 10. Modified abrasion procedure - addition of alloy balls ......

Figure 11. Modified abrasion procedure - addition of abrasive ........ 28

Figure 12. Modified abrasion procedure - addition of water ......... 28

Pigure 13. lodified abrasion procedure - abrasion test commences .......

Figure 14. Modified abrasion procedure - removal of test panels and

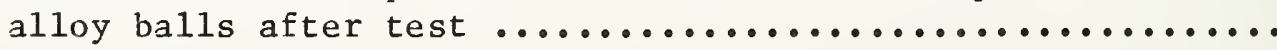

Figure 15. Modified abrasion procedure - rinsing alloy balls and

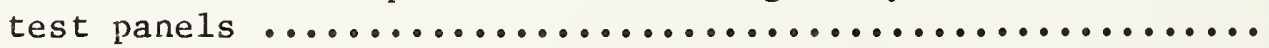

Figure 16. Adhesion procedure - yoke apparatus mounted in testing machine ......................................

Figure 17. Adhesion procedure - insertion of test panel with

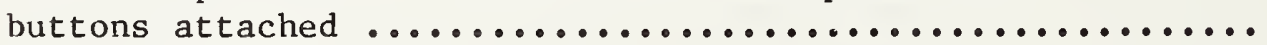

Figure 18. Adhesion procedure - joining upper and lower portions of yoke apparatus 


\section{LIST OF FIGURES - (CONTINUED)}

Page

Figure 19. Adhesion procedure - joining upper and lower portions of

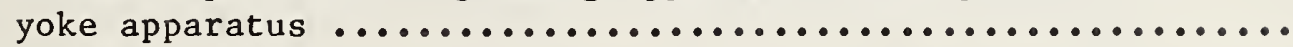

Figure 20. Adhesion procedure - after test, bottom of metallic cylinder showing delaminated coating ................. 32

Figure 21. Adhesion procedure - coated area pulled off after testing .... 33

Figure 22. Impact resistance procedure - apparatus with aluminum impactor cylinder

Figure 23. Impact resistance procedure - apparatus with test panel in place

Figure 24. Impact resistance procedure - raising impactor cylinder ..... 34

Figure 25. Impact resistance procedure - test panel after impact ...... 35

Figure 26. Stain resistance test procedure - chambers with rubber seals

Figure 27. Stain resistance test procedure - chambers inserted in upper section of holder $\ldots \ldots \ldots \ldots \ldots \ldots \ldots \ldots \ldots \ldots \ldots \ldots \ldots \ldots \ldots \ldots$

Figure 28. Stain resistance test procedure - upper holder prior to

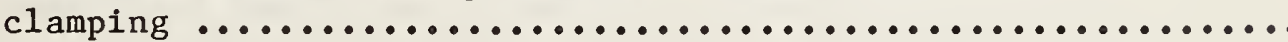

Figure 29. Stain resistance test procedure - application of liquid stain $\ldots \ldots \ldots \ldots \ldots \ldots \ldots \ldots \ldots \ldots \ldots \ldots \ldots \ldots \ldots \ldots \ldots \ldots \ldots \ldots \ldots \ldots$

Figure 30. Stain resistance test procedure - application of solid

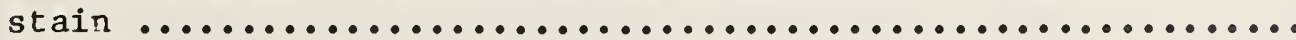

Figure 31. Stain resistance test procedure - test complete, removal

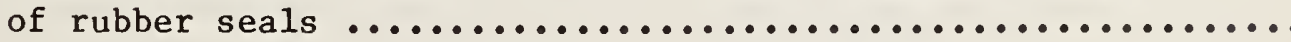

Figure 32. Average stress at rupture for various accelerated bathtub

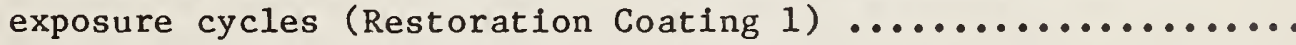

Figure 33. Average stress at rupture for various accelerated bathtub

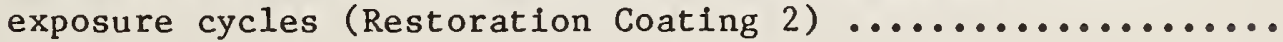

Figure 34. Average stress at rupture for various accelerated bathtub exposure cycles (Restoration Coating 3) 
Figure 35. Average stress at rupture for various accelerated bathtub

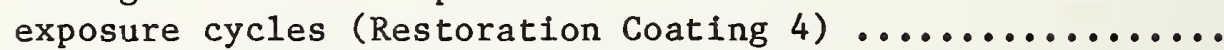

Figure 36. Average stress at rupture for various accelerated bathtub

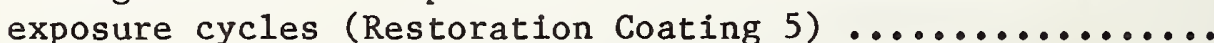

Figure 37. Restoration coating 5 after adhesion tests; left panel unexposed, center panel after two ABECs; right panel after three ABECs ................................... 


\section{INTRODUCTION}

\subsection{BACKGROUND}

Within the last 15 years, processes have been developed for restoring in place chipped or worn porcelain enamel fixtures, such as bathtubs and wash basins, hy application of an organic coating. Newer restoration techniques have been developed which may cost only one-quarter as much as replacement of the enamel-coated fixture. In the maintenance of public housing, a continuing problem exists with regards to porcelain enamel coatings on steel and cast iron fixtures which have been damaged by wear or abuse. The potential economic savings could make these new restoration techniques attractive, provided that they perform well. For example, one major problem has been that of adhesion of the organic coating to the damaged or degraded porcelain enamel surfaces. Performance criteria are needed to aid in ensuring the performance and durability of restoration coatings. Laboratory and field data, as well as accelerated test methods, are needed to serve as the technical bases for the performance criteria.

\subsection{ORJECTIVE}

The objective of the research discussed in this report was to develop interim performance criteria for restoration coatings for porcelain enamel surfaces.

\section{$1.3 \mathrm{SCOPF}$}

In order to meet the stated objective, tasks were performed to 1 ) identify the available commercial restoration coatings for the repair of porcelain enamel surfaces, 2) identify performance requirements and available test methods for evaluating restoration coatings and, where appropriate existing tests were not available, to develop new methods, 3) select and evaluate several commercial coatings in the laboratory to identify factors which affect adhesion and durability and 4) develop interim performance criteria based upon laboratory studies. The results of the above tasks are given in this report.

Field studies are currently being conducted to obtain performance and durability data on selected coatings applied to bathtubs in public housing units. These data will be used to assess the effectiveness of the interim performance criteria. Since the field studies are not yet completed, they are not addressed in this report. 


\section{IUENTIFICATION OF COMMERCIALLY AVAILABLE RESTORATION COATINGS}

Thirty five renovation firms were identified throughout the country. Eleven firms were contacted by telephone although contacts were sought with all firms. It may be noted that many of these firms also franchised other firms or were distributorships for other firms. Information sought was as follows: 1) the type of enamelled metal renovated and whether spot repairs were also made to porcelain enamel surfaces, 2) the type of surface preparation used, 3) generic coatings used, and 4) costs for renovation/repair.

The list of identified companies and information obtained from the telephone contacts are included in appendix A. To summarize the telephone responses, it was found that 1) bathtubs were the most frequently repaired units, 2) surface preparation almost always included acid, solvent and sand treatment, 3 ) the generic coatings most commonly used were urethanes and epoxies, and 4) the renovation costs for a bathtub were $\$ 175$ to $\$ 250$ versus the replacement costs estinated to be $\$ 600$ to $\$ 1000$. 


\section{PERFORMANCE REQUIREMENTS}

In order for the restoration coating to perform satisfactorily, the coating must adhere to the substrate under elevated temperature exposure and wet/dry cycling. Also, the coating should be resistant to color and gloss changes (particularly after repeated scrubbing), resistant to impact, and resistant to fungal attack and to stains when exposed to in-service use conditions.

Standard test methods were determined to be available for measuring impact resistance, color, gloss, stain resistance and fungal resistance. A modified standard method was used for measuring adhesion of coatings and a cyclic exposure test was developed to accelerate the exposure conditions experienced by a porcelain bathtub or wash basin finish. These methods are described in section 4.2 of this report. 


\section{LABORATORY EVALUATIONS}

\subsection{MATERIALS}

The surfaces of porcelain enamel-coated steel panels, obtained through the Porcelain Enamel Institute (PEI), were treated at the National Bureau of Standards to simulate four potential surface conditions that could be encountered by a restoration coating company during a restoration operation. These conditions included 1) glaze intact, 2) glaze eroded but no metal exposed, 3) glaze eroded and metal exposed and 4)glaze chipped, metal exposed with damaged substrate. Following the surface treatment, test panels were sent to five different restoration companies for restoration. The following paragraphs describe the surface treatment performed at NBS and the restoration by the five companies.

\subsubsection{Treatment of Test Panels Prior to Restoration}

The porcelain enamel coated steel panels, obtained through the PEI, were $130 \times 150 \mathrm{~mm}(4 \times 6 \mathrm{in})$ in size. These panels were considered to be representative of a "typical" new porcelain enamelled steel bathtub or wash basin. The surfaces of the test panels were subjected to one of the following four pretreatments in order to simulate various surface conditions that could be encountered prior to an actual field restoration:

Surface Condition 1. Porcelain enamel surface glaze retained intact, $1 . e .$, as received from PEI.

Surface Condition 2. Porcelain enamel surface lightly sandblasted to remove surface glaze (but metal not exposed).

Surface Condition 3. Porcelain enamel surface lightly sandblasted and then chipped with an impact tester in three locations (see pattern* in figure 1) to expose, approximately, a $19 \mathrm{~mm}$ ( $0.75 \mathrm{in})$ diameter area of the metal substrate. Prior to shipping for restoration, these panels were placed in distilled water until rust appeared.

Surface Condition 4. Porcelain enamel surface lightly sandblasted and then sandblasted to white metal in three locations (see figure 1) using a metal mask to expose $19 \mathrm{~mm}$ (0.75 in) diameter areas. Prior to shipping for restoration,

* The three locations for chipping and sandblasting were within the circular abrasion pattern created by the PEI abrasion tester $1 /$ as described in ASTM C 448 [1].

$1 /$ Certain commercial equipment, instruments or materials are identified in this paper in order to adequately specify the experimental procedure. Such identification does not imply recommendation or endorsement by the National Bureau of Standards, nor does it imply that the material or equipment identified is necessarily the best available for the purpose. 
these panels were placed in distilled water until rust appeared.

\subsubsection{Restoration Coatings}

Five restoration finish companies were selected for participation in this study to provide a cross-section of the generic coatings typically used by restoration companies. The code for the companies and the generic types of restoration coatings are as follows:

\begin{tabular}{l} 
Company Code for \\
Restoration Coatings \\
\hline
\end{tabular}

1

2

3

4
Generic Description of Coating Used

Phenolic

Epoxy

Urethane

Ename1

Urethane

Each company received 77 test panels as described in 4.1 .1 and was asked to recoat or repair them in a manner consistent with procedures used in field restorations. Thirty-five of the test panels sent to each company were pretreated using Surface Condition 1; 14 panels were sent for each of the Surface Conditions 2, 3 , and 4 . The test panels were coated at the factory using the companies' individual restoration techniques and then returned to the National Bureau of standards for laboratory testing.

\subsection{TEST METHODS}

Laboratory tests of the restored panels were performed to assess resistance to degradation using an accelerated bathtub exposure and resistance to fungal growth. Tests of adhesion, impact resistance, color, gloss, and stain resistance were performed at various exposure time increments to assess degradation. Duplicate test panels for each coating and each surface condition were kept in the laboratory as control specimens. The methods used in the laboratory tests are described below.

\subsubsection{Accelerated Bathtub Exposure}

An accelerated bathtub exposure test was developed to simulate in-service usage. It was designed to include the elements of wet and dry cycling, elevated water temperatures and surface abrasion. One accelerated bathtub exposure cycle (ABEC) included 28 bath cycles and one abrasion cycle (56 counts on the PEI abrasion tester). 
The bath portion of the exposure test, which provided wet and dry cycling and elevated water temperature exposure to the panels, utilized a modified Maytagl/ dishwasher (Model WC201). The control knob on the dishwasher was automated to provide the desired bath cycle. The electrical circuit diagram is given in figure 2 and shown in the photograph of figure 3. The bath cycle began at the setpoint on the control knob where the rinse cycle started and stopped at the drying period end point. The control knob automatically rotated from the end point (completion of drying period) to the set point (start of rinse period). During this 30 second interval, a solenoid operated valve automatically allowed liquid detergent to enter the machine. One complete bath cycle required approximately 40 minutes and the conditions are illustrated in the following table:

\begin{tabular}{|l|c|c|c|}
\hline \multicolumn{1}{|c|}{ Time Period } & $\begin{array}{c}\text { Dry Air Temp. } \\
{ }^{\circ} \mathrm{C}\left({ }^{\circ} \mathrm{F}\right)\end{array}$ & $\begin{array}{c}\text { Water Temp.4 } \\
{ }^{\circ} \mathrm{C}\left({ }^{\circ} \mathrm{F}\right)\end{array}$ & $\begin{array}{c}\text { Time } \\
\text { min. }\end{array}$ \\
\hline End point $2 /$ to set point $3 /$ & N.A. & $43(110)$ & 0.5 \\
Set point to end of wash & N.A. & $43(110)$ & 4.0 \\
Start to end of first rinse & N.A. & $43(110)$ & 5.0 \\
Start to end of second rinse & N.A. & N.A. & 23.5 \\
Start to end of drying period & $77(170)$ & & \\
\hline
\end{tabular}

Twenty-eight bath cycles were completed in each 24 hour period and the procedure is illustrated in figures 4-6. Following each 28 cycles, the panels were cooled to room temperature and visually examined for any surface defects. The abrasion portion of the exposure test was carried out at the end of each 28 bath cycles using a modification of the ASTM procedure C 448 [1] and using the PEI tester. The PEI abrasion tester was selected because it produces an

1/ Certain commercial equipment, instruments or materials are identified in this paper in order to adequately specify the experimental procedure. Such identification does not imply recommendation or endorsement by the National Bureau of Standards, nor does it imply that the material or equipment identified is necessarily the best available for the purpose.

2/ Internal timer stops, turning motor starts.

3/ Turning motor stops, internal timer begins.

4/ A previous study [2] of vitreous enamel and plastic sanitary fixtures used tests for hot water resistance and thermal shock resistance at $93.3-100^{\circ} \mathrm{C}$ to $0^{\circ} \mathrm{C}\left(200-212^{\circ} \mathrm{F}\right.$ to $\left.32^{\circ} \mathrm{F}\right)$. Frechette, et a1. [3] used a water temperature of $93.3^{\circ} \mathrm{C}\left(200^{\circ} \mathrm{F}\right)$ in studies of patch kits applied to poreclain enamel. A water temperature of $43^{\circ} \mathrm{C}$ was selected for this study because the water temperature from most residential water heaters currently is not believed to exceed $43^{\circ} \mathrm{C}\left(110^{\circ} \mathrm{F}\right)$. 
oscillating motion which simulates hand scrubbing of a porcelain fixture. The ASTM C 448 procedure was modified so that the panels were abraded for 56 machine machine counts and the abrasive used was a mild cleanser containing feldspar.1/ The ahrasion test procedure is illustrated in figures 7-15.

The panels were visually examined after $2,5,10,15,20$, and 25 ABECs and tested for changes in color, gloss, impact resistance and adhesion. The panels were rinsed with dilute hydrochloric acid and water to remove traces of salt deposits before testing. The stain and fungus tests were conducted after 25 ABECs.

\subsubsection{Adhesion}

Adhesion tests were performed to determine the level of adhesion of the restoration coatings with increasing time of accelerated exposure. The test method to determine the stress at rupture of the restoration coatings was a newly developed modification of the International Standards (ISO) method No. 4624 [4] which utilizes a pull-off technique. The adhesive used for bonding the metallic button was an industrial strength epoxy and the yoke apparatus was was especially designed for use with a testing machine. Figures 16-21 illustrate special apparatus and test procedure. Prior to bonding the metallic buttons to the panels, the panels were allowed to stabilize at $21^{\circ} \mathrm{C}\left(70^{\circ} \mathrm{F}\right)$ and 50 percent RH for at least 24 hours. A $19 \mathrm{~mm}(0.75 \mathrm{in})$ diameter, $19 \mathrm{~mm}(0.75 \mathrm{in})$ high stainless steel cylinder was glued, plane face down, with the epoxy adhesive and cured at $70^{\circ} \mathrm{C}\left(158^{\circ} \mathrm{F}\right)$ for 40 minutes. Four small spacers were machined on the outer edges of the planar surface of the stainless steel cylinder in order to produce a bond line of $0.203 \mathrm{~mm}+0.002 \mathrm{~mm}$ thickness. Three cylinders were attached at uniform intervals to duplicate coated panels having porcelain enamel Surface Condition 1. Thus, the reported stress at rupture values were an average of 6 pull-off tests. Two cylinders were attached at uniform intervals on duplicate coated panels having Surface Conditions 2, 3, and 4. Thus, stress at runture values were an average of 4 pul1-off tests for these surface conditions. For Surface Conditions 3 and 4, the cylinders were attached directly over the repaired areas that had been chipped or sandblasted. The adhesion tests were conducted using the $300 \mathrm{~kg}(661 \mathrm{lb})$ range of the testing machine with a chart drive of $50 \mathrm{~mm} / \mathrm{min}$ (2 in/min) and a console speed (movement rate of the screw drive) of $1 \mathrm{~mm} / \mathrm{min}(0.04 \mathrm{in} / \mathrm{min})$.

$1 /$ Preliminary studies with the PEI abrasion tester indicated that the alloy balls did not affect the color or gloss of the restoration finishes, but that the Pennsylvania glass sand abrasive used in the test was much too abrasive on the orsanic coatings. Preliminary studies indicated that the mild abrasive cleanser recommended by the restoration coating companies along with the alloy balls would produce moderate abrasion on the organic coatings while having little or no effect on porcelain enamel itself. 


\subsubsection{Impact Resistance}

The test method to determine the impact resistance of the restoration coatings after exposure to the accelerated exposure described in 4.2.1 was modified from ASTM D 2794 [5]. To provide improved sensitivity, a $0.45 \mathrm{~kg}$ (1 1b) aluminum impactor cylinder was used instead of the $0.9 \mathrm{~kg}$ (2 $1 \mathrm{~b})$ steel cylinder of the variable light duty impact tester. The aluminum cylinder was dropped in $25 \mathrm{~mm}$ (1 in) height increments, starting at $25 \mathrm{~mm}$ (1 in), until a visible dent or chip occurred on the surface. The coated panels used for the test were those having Surface Condition 1, (see 4.1.1). Figures 22-25 illustrate the impact resistance procedure.

\section{2 .4 Color}

ASTM test method D 2244 [6] was used to measure color differences ( $\triangle E$ ) on the coated panels after exposure to the ABECs. Using a colorimeter, measurements were made in both the abraded and unabraded areas.

\subsubsection{Gloss}

ASTM test method D 523 [7] was used to measure $60^{\circ}$ gloss differences on the coated panels after exposure to ABECs. Gloss measurements were made in both the abraded and unabraded areas. Preliminary gloss measurements revealed the necessity of removing traces of minerals or other deposits from the tap water and detergents used in the bath cycle. Consequently, a dilute hydrochloric acid wash and distilled water rinse was an essential part of panel preparation before gloss measurements were made.

\subsubsection{Stain Resistance}

Test panels were rated visually for effectiveness of stain removal. The measurement of stain resistance involved modification of the test method ASTM D 1308 [8]. The test apparatus was the same as that used in a previous study [2]. In particular, the procedures were modified to ensure that the staining materials would not evaporate during the 16 hour exposure. The staining materials selected were those thought to be in common usage in bathroom areas and those which had proved troublesome on other organic substrate such as fiber glass reinforced polyester bathtubs [2] and plastic wall covering materials [9]. These staining materials were purple Tintex, black hair dye, black shoe polish, lipstick and acetone. The test apparatus and its use is illustrated in figures 26 to 31 . The stains were removed after 16 hours exposure on the restoration coating using the following three methods:

Method 1 - wipe with soft dry paper towe1,

Method 2 - scrub gent1y with warm soapy water and brush, and

Method 3 - scrub on PEI abrasion tester for 28 cycles.

The panels used for this test were Surface Conditions 1 and 2, (see 4.1.1) which had been exposed to the ABECs. Surface Conditions 3 and 4 panels were not used 
for this test because staining is a surface related phenomena and the restoration coating surfaces of Surface Condition 3 and 4 panels were comparable to those of Surface Condition 1 and 2 panels.

\subsubsection{Fungal Resistance}

Measurement of fungal resistance was by test method ASTM D 3273 [10]. The coated test panels were examined in accordance with test method ASTM D 3274 [11] after 30 days exposure in the incubation chamber. 


\section{RESULTS AND DISCUSSION}

\subsection{ADHESION}

The change in measured stress at rupture of the test panels with ABECs is given in figures 32-36 for Restoration Coatings 1, 2, 3, 4, and 5. Prior to exposure, to range of measured stress at rupture values for all surface conditions of each Restoration Coating were as follows: Restoration Coating 1: $3.0 \mathrm{MPa} 1 /$ (430 psi) the $1.7 \mathrm{MPa}$ (250 psi); Restoration Coating 2: $2.6 \mathrm{MPa}$ (375 psi) to $1.4 \mathrm{MPa}$ (200 psi); Restoration Coating 3: $2.8 \mathrm{MPa}$ ( $400 \mathrm{psi}$ ) to $1.8 \mathrm{MPa}$ (260 psi); Restoration Coating 4: $5.2 \mathrm{MPa}$ (750 psi) to $1.7 \mathrm{MPa}$ (250 psi); and Restoration Coating 5: $4.3 \mathrm{MPa}(630 \mathrm{psi})$ to $1.9 \mathrm{MPa}$ (275 psi). The surface condition of the panels prior to restoration/repair had an influence on the stress at rupture of the restored/repaired panels. The stress at rupture of panels of Surface Conditions 1 and 2 would have been expected to have been nearly equal. The lower stress at rupture values of Surface Condition 2 panels may have been the result of the sandblasting treatment treatment causing microcracking which weakened the cohesive bonding of the porcelain enamel. The stress at rupture values of Surface Condition 3 and 4 panels were usually lower than the others. Also, the values were more erratic for Surface Conditions 3 and 4 than for Surface Conditions 1 and 2, which may reflect the influences of the epoxy fillers used for the repair and the stresses imposed on the panels during impact and sandblasting treatment. The stress at rupture of all the restoration coatings decreased with increasing number of exposure cycles. However, the rate of decreasing stress at rupture with ABECs was noticeably different for the different restoration coatings. As examples, 1) the stress at rupture of Restoration Coating 5, Surface Condition 1, decreased rapidly from 4.3 MPa (630 psi) to $1.9 \mathrm{MPa}$ (275 psi) after 2 ABECs before stabilization, and 2) the stress at rupture of Restoration Coating 4, Surface Condition 1 , decreased from 5.2 $\mathrm{MPa}$ (750 psi) initially to $3.7 \mathrm{MPa}$ (537 psi) after $25 \mathrm{ABECs}$. For each of the coatings, the general shape of the ABEC curve for Surface Conditions 2, 3, and 4 was similar to that of the Surface Condition 1 curve. This implies that the properties of each of the restoration coatings were a more important factor in the degradation process than the individual surface condition treatments.

When the average stress at rupture was greater than $4.1 \mathrm{MPa}$ (600 psi), failures occurred in the porcelain enamel-metal interface. For example, all of the panels of Restoration Coating 4, Surface Condition 1, delaminated in the porcelain enamel for up to $20 \mathrm{ABECs}$, while none of the panels of Restoration Coating 1, Surface Condition 1, delaminated in the porcelain enamel following accelerated exposure. Also of interest, the mode of adhesion failure changed with a decrease in average stress at rupture as exposure cycles increased. This is illustrated in figure 37 for Restoration Coating 5, Surface Condition 1; the initial failure was in the porcelain enamel substrate; after two ABECs, failure was observed at the primer to organic top coat interface; and after three ABECs, cohesive failure occurred within the organic top coat. The mode

$1 / \mathrm{MPa}=$ mega pascal. 
of failure in order of decreasing frequency was 1) failure in the enamel, 2) primer-to-top coat failure, and 3) cohesive failure in the top coat. The latter failure mode was primarily observed as the stress at rupture values decreased with increasing exposures. In general, stress at rupture values of the restoration coatings over repaired areas (Surface Conditions 3 and 4 ) were not as high as those for Surface Conditions 1 and 2. Influences other than the test exposure on the adhesion of the restoration coatings may have been the thickness of coating and/or filler surface treatment, stress concentrations from bonding to the relatively thin steel substrate, and the air and water temperatures used in the bath cycles which may have accelerated polymer degradation.

\subsection{IMPACT RESISTANCE}

The average impact resistance of the restoration coatings was determined by a modification of ASTM D 2794 [5] after exposure to ABECs. The results are shown in table 1. For comparison purposes, the impact resistance test was also performed on unrestored porcelain enamel panels, Surface Condition 1. The average impact resistance of six of these panels was $0.53 \mathrm{Nm}$.

All the restoration coatings had better initial impact resistance than the unrestored porcelain enamel panel. The change in impact resistance of the restoration coatings after exposure was small and considered insignificant.

\subsection{COLOR}

Color difference measurements were made on both the abraded and unabraded areas of the restoration coatings after exposure to ABECs. The results of coatings, Surface Condition 1, are illustrated in table 2. For comparison purposes, color measurements were performed on unrestored porcelain enamel panels, Surface Condition 1. These data are included at the bottom of table 2. The color differences of Restoration Coatings, Surfaces Conditions 2, 3 and 4, are illustrated in table 3 after 25 ABECs.

The color changes for the restoration coatings after accelerated exposures were generally 2 NBS color difference units or less and thus, color changes are considered insignificant. Restoration Coating 2 (table 3), was an exception in that color changes were visible. Varying panel surface conditions did not affect the color changes after accelerated exposures except for possible minor effects due to surface differences (defects).

\subsection{GLOSS}

The $60^{\circ}$ gloss measurements were made on both the abraded and unabraded areas of the restoration coatings after exposures. The test results of coatings, Surface Condition 1, are illustrated in table 4. For comparison purposes, gloss measurement was also performed on unrestored porcelain enamel panels, Surface Condition 1. These data are shown at the bottom of table 4. The gloss measurements of restoration coatings, for Surface Conditions 2, 3, and 4, after 25 ABECs are illustrated in table 5. 
Gloss changes for the restoration coatings after accelerated exposures, i.e., 25 ABECs, in the unabraded areas were minor. However, large gloss changes were found in the abraded areas for all restoration coatings. The unrestored porcelain enamel panel, Surface Condition 1, had a 21 percent loss in gloss in the abraded area after 25 ABECs. While the abrasive used in the tests is of a type recommended for restoration coating and fiber glass reinforced polyester bathtubs, its use in this study proved to be devastating on the gloss of the finishes. The abrasive medium for organic coatings should be a softer inorganic material or an organic fibrous material, e.g., Nylon mats, in order to retain gloss.

\subsection{STAIN RESISTANCE}

The stain test results are given in table 6 for the restoration coatings, Surface Condition 2, which had been exposed to 25 ABECs. In preliminary experiments, unrestored porcelain enamel coatings were completely resistant to all of the stain materials. With the exceptions of the effects of the black hair dye on Restoration Coatings 2 and 3, and the effects of acetone in dissolving Restoration Coatings 1,3 , and 5 , the stains were readily removed from the coatings.

\subsection{FUNGAL RESISTANCE}

Since restoration coatings would often be exposed to fungi growth in a hot, hunid bathroom environment, the procedure in test method ASTM D 3273 was used to exanine' the fungi resistance of these materials. After 30 days test exposure of the five restoration coatings, and an unrestored porcelain enamel panel, which had previously been exposed to 25 ABECs, no fungal growth was observed on any of the panels. 


\section{INTERIM PERFORMANCE CRITERIA}

Interim performance criteria for restoration coatings for porcelain enamel surfaces are presented in appendix $B$ and are based upon the laboratory test results described in chapter 5 of this report. These performance criteria are termed "interim" because they may be modified after the completion of the field studies.

The key to the development of the performance criteria was exposure of the test panels to accelerated bathtub exposure cycling (ABEC) which included wet and dry cycling, elevated water temperatures and surface abrasion. All panels were exposed to 25 ABECs (each cycle included 28 bath cycles with detergent injection at each bath cycle, then cooling and abrading the panels on the PEI abrasion tester for 56 machine counts using feldspar-containing cleanser and the alloy balls as abrasive before evaluation). The criteria selected were chosen to reflect performance characteristics which these materials would be expected to exhibit in service; they included appearance, abrasion resistance, adhesion, impact resistance, stain resistance and fungal resistance.

Based upon the laboratory test results, all of the five restoration coatings had good performance with regard to appearance, impact resistance, stain resistance, and fungal resistance which is reflected in the respective proposed test requirements. The proposed test requirements are as follows:

- Appearance: $60^{\circ}$ gloss: Before exposure $-\geq 75$

After 25 ABECs $-\geqslant 70$

$45^{\circ}$ reflectance: Before exposure $-\geqslant 85$

color change: After 25 ABECs $-<2$ NBS units

- Impact resistance: $\frac{\geq}{25} 0.53 \mathrm{ABECs}(4.7$ inch pounds) after exposure to

- Stain resistance: very light stain residue after scrubbing with warm soapy water on specimens exposed to 25 ABECs

- Fungal resistance: no fungus after 30 days exposure to conditions of ASTM D 3273 (i.e., rating 10, ASTM D 3274).

Test data indicated differences in stress at rupture for adhesion tests in both the initial and exposed restoration coatings. The adhesion test requirement is proposed of a $3.1 \mathrm{MPa}$ (450 psi), initial, and $1.4 \mathrm{MPa}$ (200 psi), after exposure to 25 ABECs. This is thought to represent the criteria for heavy use areas, e.g., children, transient tenants, whereas the adhesion criteria may well be modified for use in light use areas, e.g., elderly occupants. At this time, the interim performance criteria do not differentiate between various use conditions. The additional field test study should aid in the validation of the interim criteria and provide guidance in differentiating criteria for different use areas. 


\section{SUMMARY AND CONCLUSIONS}

An accelerated bathtub exposure cycle (ABEC) was developed to study the performance of restoration coatings for porcelain enamel surfaces. The exposure test contained the elements of elevated water tempertures, wet and dry cycling and surface abrasion. Five companies applied restoration coatings to porcelain enamel panels which had been treated to simulate various conditions of surfaces in need of repair. The restored panels were exposed to the accelerated exposures for selected time periods prior to evaluation. Performance characteristics of the restoration coatings examined included appearance, adhesion, impact resistance, stain resistance and fungal resistance. Interim performance criteria were developed based upon these characteristics of the five restoration coatings.

General conclusions based upon the laboratory results are as follows:

1. Adhesion was the performance characteristic most sensitive to change with the length of time of accelerated exposure. Damage to the porcelain enamel surface during sandblast surface preparation and prior to restoration coating application appeared to have had a noticeable deleterious effect on stress at rupture. This could be of concern in future restoration procedures.

2. The restoration coatings examined had good performance with regards to appearance, impact resistance, stain resistance, and fungal resistance.

3. The use of the feldspar-containing cleanser in the PEI abrasion tester was judged to be too severe for the restoration coatings tested. This conclusion is based upon the large changes in gloss in abraded areas of test specimens. While a housewife cleaning a bathtub with a feldspar-containing cleanser ordinarily would not abrade a bathtub under the severe conditions used in the PEI abrasion test, consideration should be given to the development of an even milder abrasive for use with restoration coatings. Also, modification of test procedures for measuring abrasion resistance and resultant gloss changes will require milder abrasives for more sensitive detection of changes. 


\section{FUTURE RESEARCH}

The interim performance criteria presented in appendix $B$ for restoration coatings for porcelain enamel are based only upon accelerated exposure tests and require field testing to validate the interim criteria. As pointed out in previous sections of the report, field tests are currently underway. The effectiveness of the adhesion test in assessing changes in coatings performance necessitates the use of adhesion tests in the field test study. The development of a portable pneumatic adhesion tester is needed to permit these tests to be carried out; research is currently underway to develop a portable tester. Research is also needed to determine the effects of surface preparation treatments prior to restoration coating application. The development of non-abrasive cleansers for use with restoration coatings is needed. 


\section{ACKNOWLEDGMENTS}

The authors thank Mr. Larry Masters, Dr. Mary McKnight and Mr. Harvey Berger of NBS for their helpful guidance and assistance in preparing this report, Mr. Jack Lee of NBS for his dedicated laboratory work and collation of data and Mr. Ronald Morony and Ms. Dorothy Allen of HUD and Mr. Richard Moss, PEI, for their helpful guidance and assistance. Also, we wish to thank the Department of Housing and Urban Development for supporting this research and the manufacturers and suppliers who provided materials and assistance in this project. 


\section{REFERENCES}

[1] "Tests for Abrasion Resistance of Porcelain Enamels," C 448, ASTM Book of Standards, Part 17, American Society for Testing and Materials, Philadelphia, PA 19103, 1980.

[2] Building Research Division, Institute of Applied Technology, "Investigation of Performance Characteristics for Sanitary Plumbing Fixtures," NBS Report 8975, National Bureau of Standards, Washington, D.C., September 1965.

[3] Frechette, V.D., Holleran, L.M., Pasto, A., and Quackenbush, C.L.W., "Commercial Patch Test Kits - Tests and Evaluation," Proceedings of the Porcelain Enamel Institute Technical Forum, Porcelain Enamel Institute, Inc., Washington, D.C., Volume 30, 1968.

[4] "Paints and Varnishes - Pull-off Test for Adhesion," International Standard ISO $4624,1978$.

[5] "Test for Resistance of Organic Coatings to the Effects of Rapid Deformation (Impact)", D 2794, ASTM Book of Standards, Part 27, American Society for Testing and Materials, Philadelphia, PA 19103, 1980 .

[6] "Instrumental Evaluation Color Differences of Opaque Materials," D 2244, ASTM Book of Standards, Part 27, American Society for Testing and Materials, Philadelphia, PA 19103, 1980.

[7] "Test for Specular Gloss," D 523, ASTM Book of Standards, Part 27 , American Society for Testing and Materials, Philadelphia, PA 19103, 1980.

[8] "Tests for Effect of Household Chemicals on Clear and Pigmented Organic Finishes," D 1308, ASTM Book of Standards, Part 27, American Society for Testing and Materials, Philadelphia, PA 19103, 1980.

[9] Clark, Elizabeth J. and Campbe11, Paul G., "Evaluation of Plastic Wallcovering Materials," NBS Technical Note 984, National Bureau of Standards, October 1978.

[10] "Test for Resistance to Growth of Mold on the Surface of Interior Coatings in an Environmental Chamber," D 3273, ASTM Book of Standards, Part 27, American Society for Testing and Materials, Philadelphia, PA 19103,1980 .

[11] "Evaluating Degree of Surface Disfigurement of Paint Films by Fungal Growth on Soil and Dirt Accumulation," D 3274, ASTM Book of Standards, Part 27, American Society for Testing and Materials, Philadelphia, PA 19103,1980 . 
Table 1. Average Impact Resistance of Restoration Coatings, Surface Condition 1, After ABECs

Impact Resistance $(\mathrm{Nm})$ *

\begin{tabular}{|c|c|c|c|c|c|c|c|}
\hline $\begin{array}{c}\text { Company Code for } \\
\begin{array}{c}\text { Restoration } \\
\text { Coating }\end{array}\end{array}$ & 0 & 2 & 5 & 10 & 15 & 20 & 25 \\
\hline 1 & 0.87 & 0.82 & 0.84 & 0.84 & 0.79 & 0.82 & 0.84 \\
\hline 2 & 0.59 & 0.62 & 0.56 & 0.67 & 0.56 & & 0.67 \\
\hline 3 & 0.82 & & 0.79 & 0.67 & 0.79 & & 0.84 \\
\hline 4 & 0.87 & 0.79 & 0.82 & 0.79 & 0.81 & 0.73 & 0.80 \\
\hline 5 & 0.79 & 0.65 & 0.76 & 0.67 & 0.67 & 0.67 & 0.64 \\
\hline
\end{tabular}

* Each value is an average in Newton meters of four measurements.

Table 2. Color Differences of Restoration Coatings, Surface Condition 1, After ABECs

Color Difference

\begin{tabular}{|c|c|c|c|c|c|c|c|c|c|c|c|c|}
\hline \multirow{3}{*}{$\begin{array}{c}\text { Company Code for } \\
\text { Restoration } \\
\text { Coating } \\
\end{array}$} & \multicolumn{12}{|c|}{$A B E C S$} \\
\hline & \multicolumn{2}{|c|}{2} & \multicolumn{2}{|c|}{5} & \multicolumn{2}{|r|}{10} & \multicolumn{2}{|c|}{15} & \multicolumn{2}{|c|}{20} & \multicolumn{2}{|c|}{25} \\
\hline & $A^{*}$ & $\mathrm{U}^{*}$ & $\mathrm{~A}$ & $\mathrm{U}$ & $\mathrm{A}$ & $\mathrm{U}$ & $\mathrm{A}$ & $\mathrm{U}$ & $\mathrm{A}$ & $\mathrm{U}$ & $\mathrm{A}$ & $\mathrm{U}$ \\
\hline $\begin{array}{l}1 * * \\
4 \\
5\end{array}$ & $\begin{array}{l}0.93 \\
1.37 \\
2.43\end{array}$ & $\begin{array}{l}0.41 \\
0.40 \\
0.34\end{array}$ & $\begin{array}{l}1.28 \\
1.58 \\
1.87\end{array}$ & $\begin{array}{l}0.59 \\
0.50 \\
0.24\end{array}$ & $\begin{array}{l}1.33 \\
1.39 \\
2.42\end{array}$ & $\begin{array}{l}0.48 \\
0.34 \\
0.49\end{array}$ & $\begin{array}{l}1.70 \\
1.16 \\
2.47\end{array}$ & $\begin{array}{l}0.80 \\
0.54 \\
0.33\end{array}$ & $\begin{array}{l}1.64 \\
1.4 \\
2.51\end{array}$ & $\begin{array}{l}0.98 \\
0.70 \\
0.47\end{array}$ & $\begin{array}{l}1.77 \\
1.37 \\
2.54\end{array}$ & $\begin{array}{l}1.00 \\
0.74 \\
0.32\end{array}$ \\
\hline $\begin{array}{l}\text { Unrestored } \\
\text { Porcelain } \\
\text { Enamel } * * *\end{array}$ & 0.35 & 0.59 & 0.52 & 0.56 & 0.71 & 0.74 & 0.50 & 0.53 & 0.95 & 1.22 & 0.55 & 0.36 \\
\hline
\end{tabular}

$*_{\mathrm{A}}=$ abraded area, $\mathrm{i} . e .$, PEI abrasion test area; ${ }^{\mathrm{U}} \mathrm{U}=$ unabraded area

** Restoration coatings 2 and 3 were not included because of insufficient specimens

*** The unrestored porcelain enamel specimens, Surface Condition 1, were included as a basis for comparison of restoration coatings with porcelain enamel. 
Table 3. Color Differences of Restoration Coatings, Surface Conditions 2, 3, and 4, After 25 ABECs

\begin{tabular}{|c|c|c|c|}
\hline $\begin{array}{l}\text { Company Code } \\
\text { for } \\
\text { Restoration } \\
\text { Coating }\end{array}$ & $\begin{array}{l}\text { Surface } \\
\text { Condition }\end{array}$ & $\begin{array}{r}\text { Color } \\
A^{*}\end{array}$ & $\begin{array}{c}\text { Difference } \\
U^{*}\end{array}$ \\
\hline \multirow[t]{3}{*}{0} & 2 & 1.16 & 0.34 \\
\hline & 3 & 0.75 & 0.74 \\
\hline & 4 & 0.63 & 0.62 \\
\hline \multirow{3}{*}{2} & 2 & 3.01 & 3.24 \\
\hline & 3 & 5.52 & 3.17 \\
\hline & 4 & 4.51 & 3.23 \\
\hline \multirow{3}{*}{3} & 2 & 1.10 & 1.44 \\
\hline & 3 & 0.69 & 0.98 \\
\hline & 4 & 0.88 & 0.92 \\
\hline \multirow{3}{*}{4} & 2 & 1.77 & 1.16 \\
\hline & 3 & 1.87 & 1.25 \\
\hline & 4 & 1.83 & 1.33 \\
\hline \multirow{3}{*}{5} & 2 & $\overline{0.94}$ & 0.59 \\
\hline & 3 & 1.05 & 0.52 \\
\hline & 4 & 1.40 & 0.80 \\
\hline
\end{tabular}

${ }^{*} \mathrm{~A}=$ abraded area, $\mathrm{i} . e .$, PEI abrasion test; ${ }^{\mathrm{U}} \mathrm{U}=$ unabraded area

Table 4. $60^{\circ}$ Gloss of Restoration Coatings, Surface Condition 1 , After ABECs

Gloss

\begin{tabular}{|c|c|c|c|c|c|c|c|c|c|c|c|c|c|}
\hline \multirow{3}{*}{$\begin{array}{l}\text { Company Code for } \\
\text { Restoration } \\
\text { Coating }\end{array}$} & \multicolumn{13}{|c|}{$A B E C S$} \\
\hline & \multirow[t]{2}{*}{0} & \multicolumn{2}{|c|}{2} & \multicolumn{2}{|c|}{5} & \multicolumn{2}{|c|}{10} & \multicolumn{2}{|c|}{15} & \multicolumn{2}{|c|}{20} & \multicolumn{2}{|c|}{25} \\
\hline & & $A^{*}$ & $U^{*}$ & A & $\mathrm{U}$ & A & U & A & $\mathrm{U}$ & A & $\mathrm{U}$ & A & U \\
\hline 1 & 53 & 47 & 67 & 36 & 58 & 22 & 63 & 16 & 65 & 12 & 54 & $\overline{9}$ & 50 \\
\hline 2 & 94 & 59 & 93 & 45 & 92 & 29 & 91 & $=$ & - & - & - & 18 & 78 \\
\hline 3 & 92 & - & - & 55 & $\overline{92}$ & 28 & 88 & 18 & 88 & - & - & 7 & 81 \\
\hline 4 & 92 & 42 & 92 & 32 & 78 & 15 & 87 & 9 & $\overline{92}$ & 7 & 84 & 5 & 90 \\
\hline 5 & 76 & 66 & 79 & $\overline{45}$ & 71 & 23 & 81 & 16 & 82 & 11 & 70 & 11 & 70 \\
\hline $\begin{array}{c}\text { Unrestored porce- } \\
\text { lain enamel }\end{array}$ & 98 & 99 & 99 & 100 & 100 & 93 & 96 & 89 & 97 & 82 & 96 & 75 & 95 \\
\hline
\end{tabular}


Table 5. $60^{\circ}$ Gloss of Restoration Coatings, Surface Conditions 2,3 , and 4, After 25 ABECs

\begin{tabular}{|c|c|c|c|}
\hline $\begin{array}{c}\text { Company code } \\
\text { for } \\
\text { Restoration } \\
\text { Coating } \\
\end{array}$ & $\begin{array}{c}\text { Surface } \\
\text { Condition }\end{array}$ & $\begin{array}{r}60^{\circ} \\
\mathrm{A}^{*}\end{array}$ & $\begin{array}{c}\text { Gloss } \\
\mathrm{U}^{*}\end{array}$ \\
\hline \multirow{3}{*}{1} & 2 & 7 & 79 \\
\hline & 3 & 13 & 74 \\
\hline & 4 & 11 & 72 \\
\hline \multirow{3}{*}{2} & 2 & 42 & 89 \\
\hline & 3 & 36 & 89 \\
\hline & 4 & 34 & 89 \\
\hline \multirow{3}{*}{3} & 2 & 10 & 83 \\
\hline & 3 & 10 & 87 \\
\hline & 4 & 8 & 82 \\
\hline \multirow{3}{*}{4} & 2 & 6 & 91 \\
\hline & 3 & 6 & 93 \\
\hline & 4 & 5 & 89 \\
\hline \multirow{3}{*}{5} & 2 & 25 & 84 \\
\hline & 3 & 24 & 76 \\
\hline & 4 & 28 & 81 \\
\hline
\end{tabular}

${ }^{*} \mathrm{~A}=$ abraded area, $\mathrm{i} . \mathrm{e} .$, PEI abrasion test area; $* U$ = unabraded area 
Table 6. Stain Resistance of Restoration Coatings Using Three Removal Methods $1 /$

Method 1

\begin{tabular}{|c|c|c|c|c|c|}
\hline $\begin{array}{c}\text { Company Code } \\
\text { Restoration } \\
\text { Coating }\end{array}$ & $\begin{array}{c}\text { Purple } \\
\text { Tintex }\end{array}$ & $\begin{array}{c}\text { Black } \\
\text { Hair Dye }\end{array}$ & Acetone & $\begin{array}{c}\text { Black Shoe } \\
\text { Polish }\end{array}$ & Lipstick \\
\hline \multirow{2}{*}{1} & & & & & \\
& VL & L & DS & VL & L \\
& VL & L & DS & VL & L \\
\hline 2 & L & D & NE & VL & VL \\
& L & D & NE & VL & VL \\
\hline 3 & L & D & DS & L & L \\
& L & D & DS & L & L \\
\hline 4 & L & L & NE & L & L \\
& L & L & NE & L & L \\
\hline 5 & VL & L & DS & VL & L \\
& VL & L & DS & VL & L \\
\hline
\end{tabular}

Method 2

Method 3

\begin{tabular}{|c|c|c|c|c|c|c|c|c|}
\hline $\begin{array}{c}\text { Company Code } \\
\begin{array}{c}\text { Restoration } \\
\text { Coating }\end{array}\end{array}$ & $\begin{array}{c}\text { Purple } \\
\text { Tintex }\end{array}$ & $\begin{array}{c}\text { Black } \\
\text { Hair Dye }\end{array}$ & $\begin{array}{c}\text { Black Shoe } \\
\text { Polish }\end{array}$ & Lipstick & $\begin{array}{c}\text { Purple } \\
\text { Tintex }\end{array}$ & $\begin{array}{c}\text { Black } \\
\text { Hair Dye }\end{array}$ & $\begin{array}{c}\text { Black Shoe } \\
\text { Polish }\end{array}$ & Lipstick \\
\hline \multirow{2}{*}{1} & & & & & & & & \\
& VL & L & VL & VL & VL & L & VL & R \\
& VL & L & VL & VL & VL & L & R \\
\hline 2 & VL & D & VL & R & VL & D & VL & - \\
& VL & D & VL & R & VL & D & R & - \\
\hline 3 & VL & D & VL & VL & VL & D & VL & VL \\
& VL & D & VL & VL & VL & D & VL & VL \\
\hline 4 & R & L & VL & VL & - & L & VL & VL \\
& R & L & VL & VL & - & L & VL & VL \\
\hline 5 & R & VL & R & R & - & L & - & - \\
& R & VL & R & R & - & L & - & - \\
\hline
\end{tabular}

$1 /$ Method 1 - Wipe with soft dry paper towel

2 - Scrub gently with warm soapy water and brush

3 - Scrub on PEI tester 28 cycles

Description of Abbreviations
$\mathrm{R}$ - Stain removed
NR - Stain not removed
VL - Very light strain remained
L - Light stain remained
D - Dark stain remained

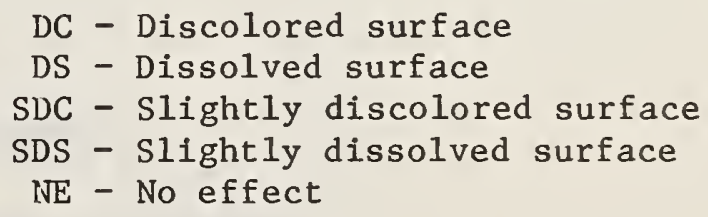




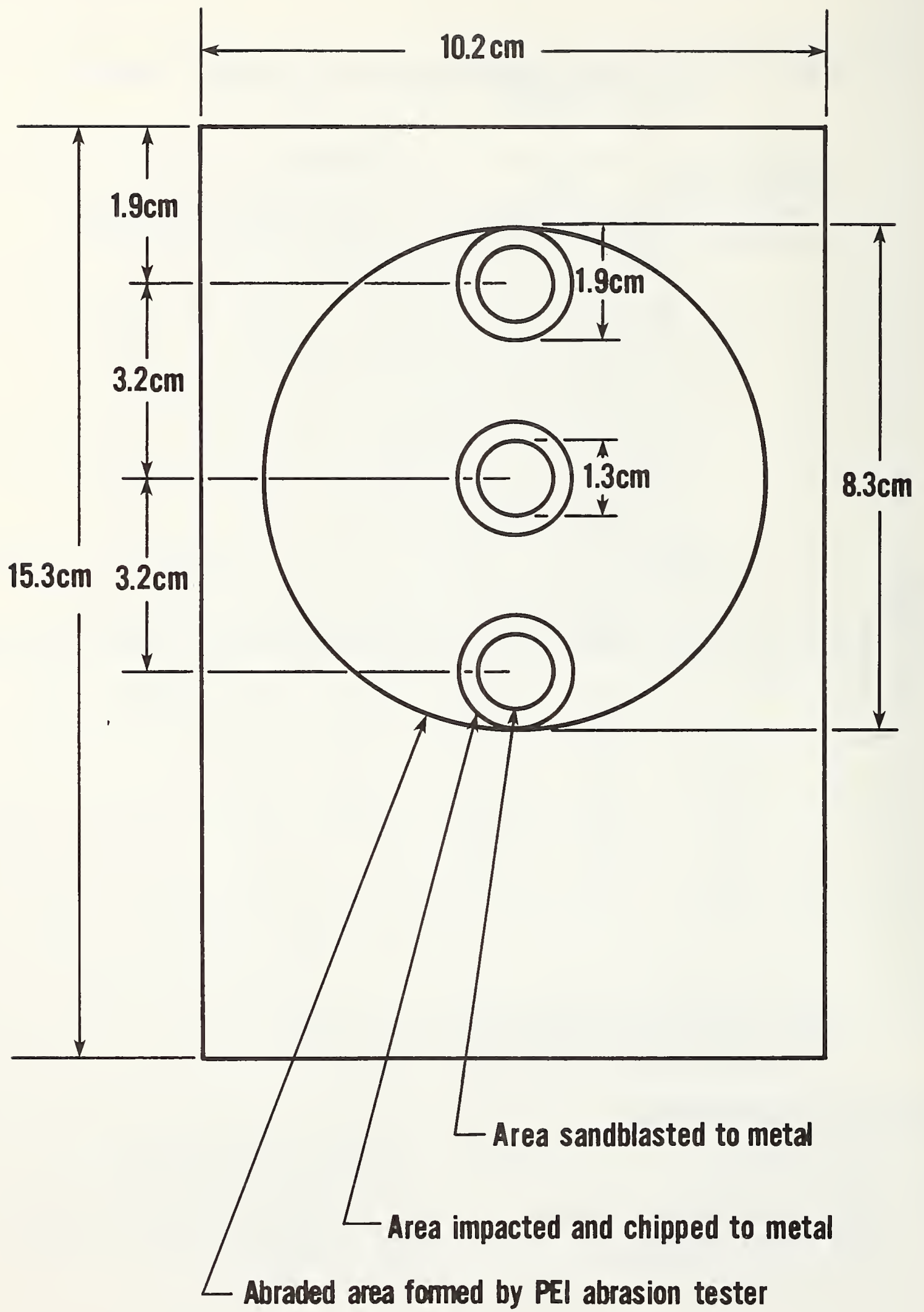

Eigure 1. Pattern for preconditioning test panels 


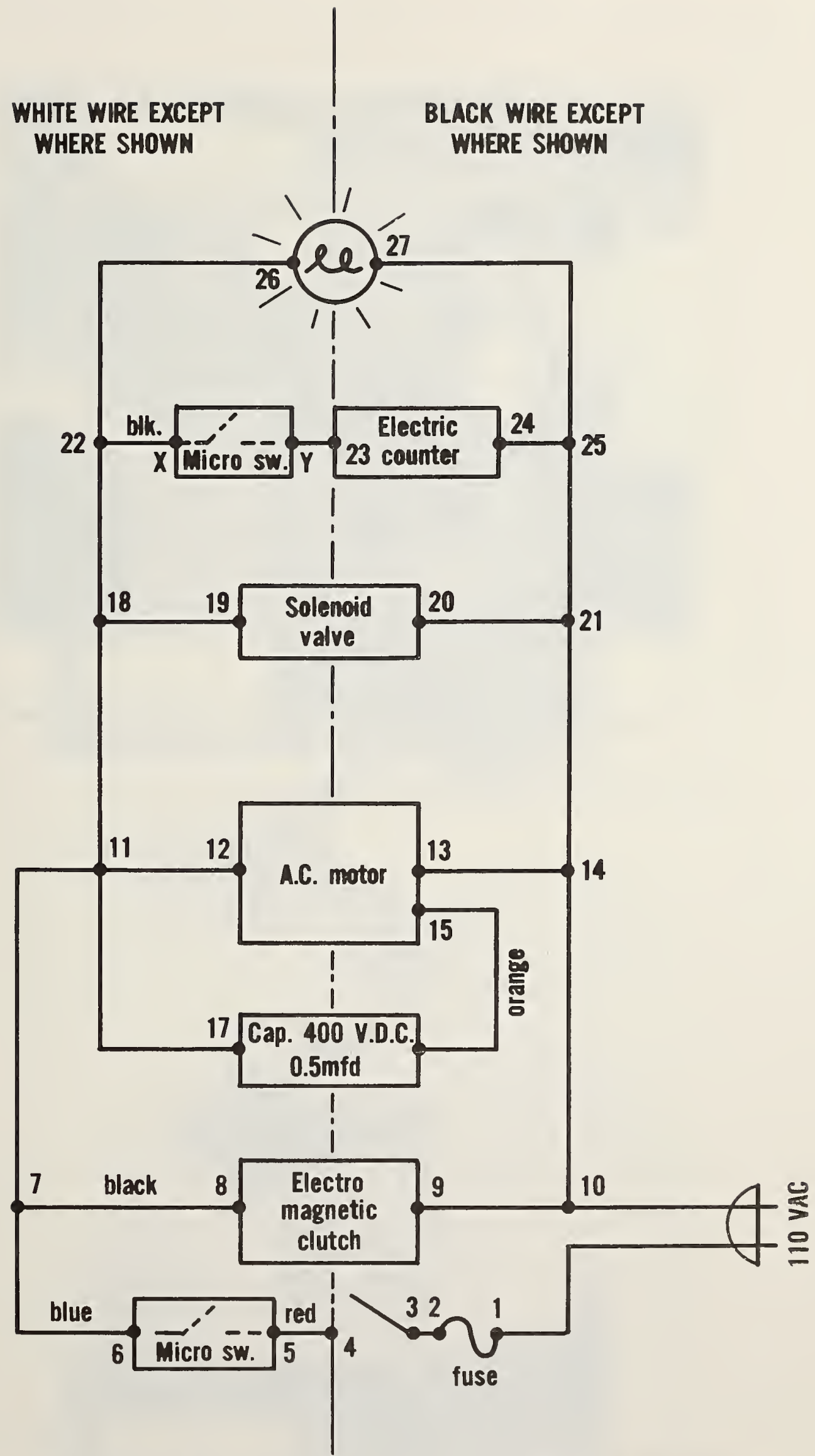

Figure 2. Circuit diagrain for recycling controls on modified dishwasher 


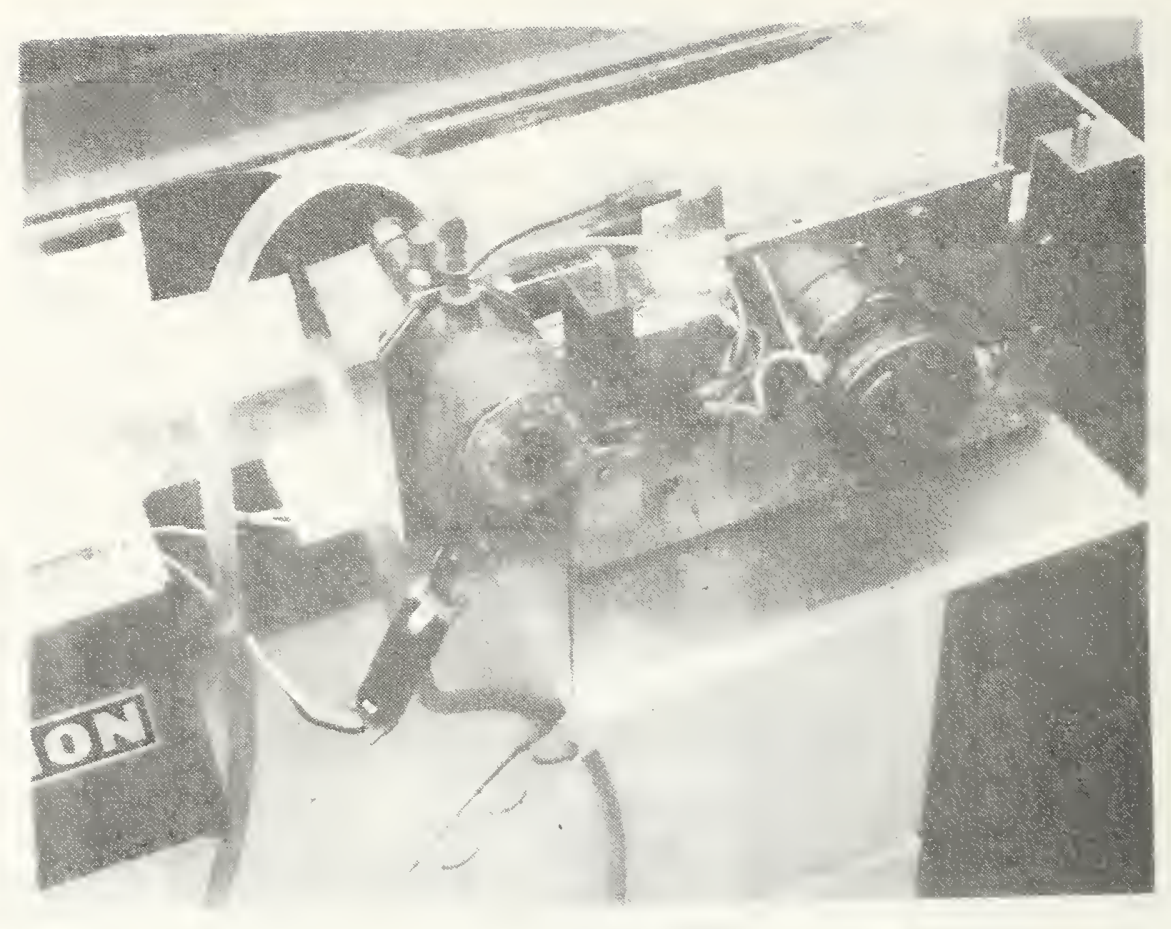

Figure 3. Recycling controls on modified dishwasher

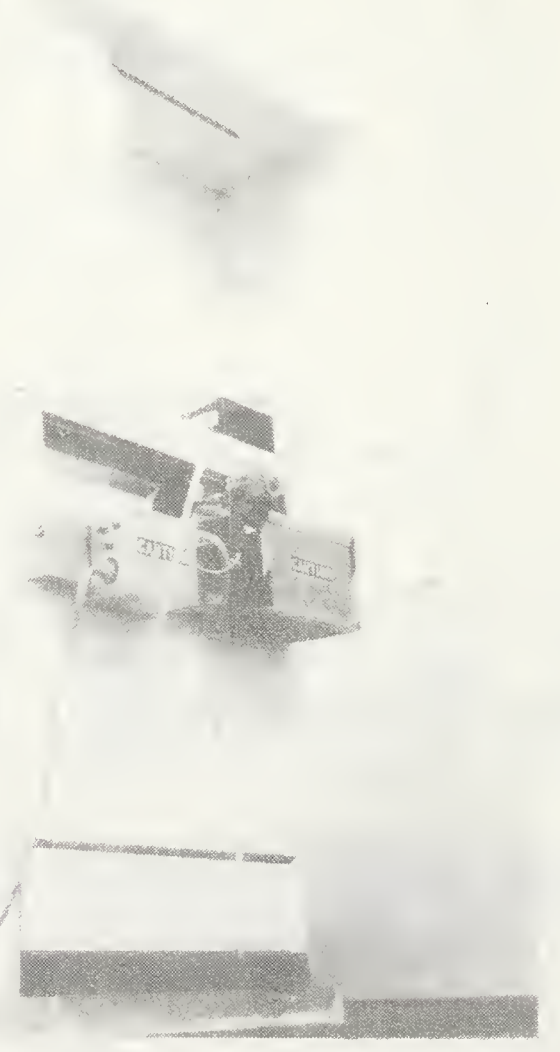

Figure 4. Accelerated bath cycle apparatus - overall view 

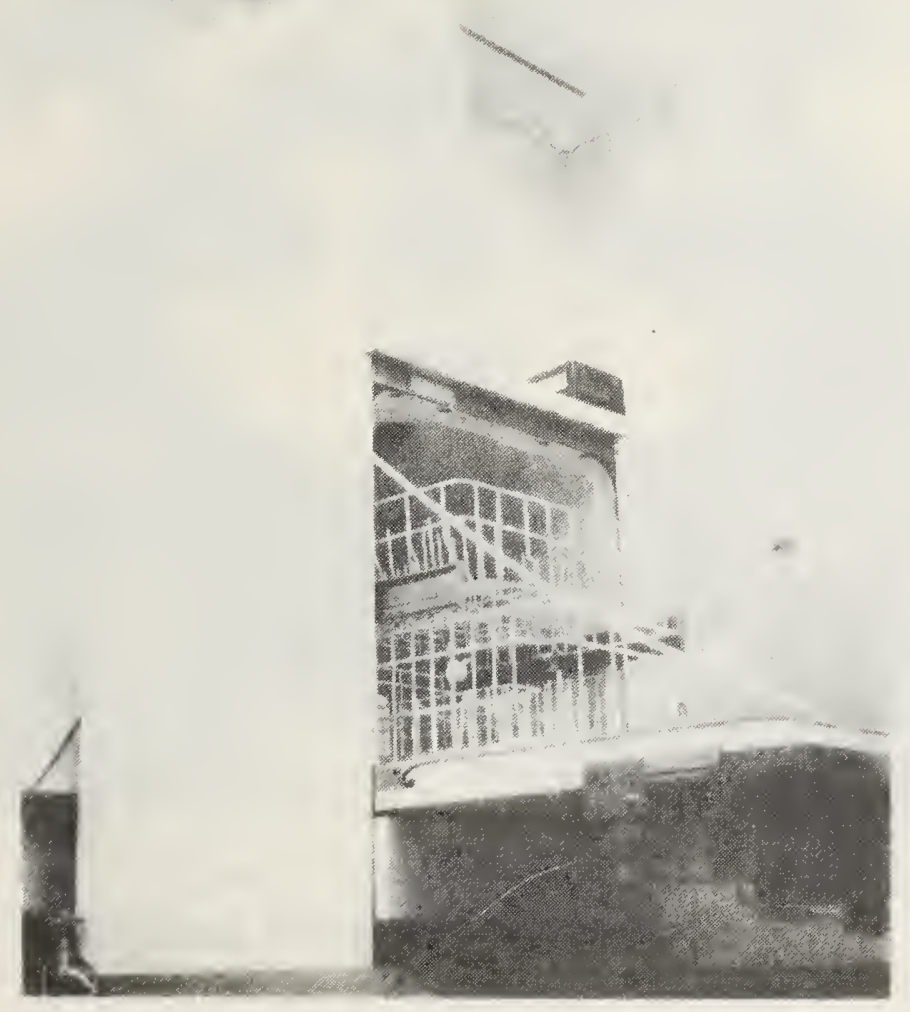

Figure 5. Accelerated bath cycle apparatus - machine unloaded
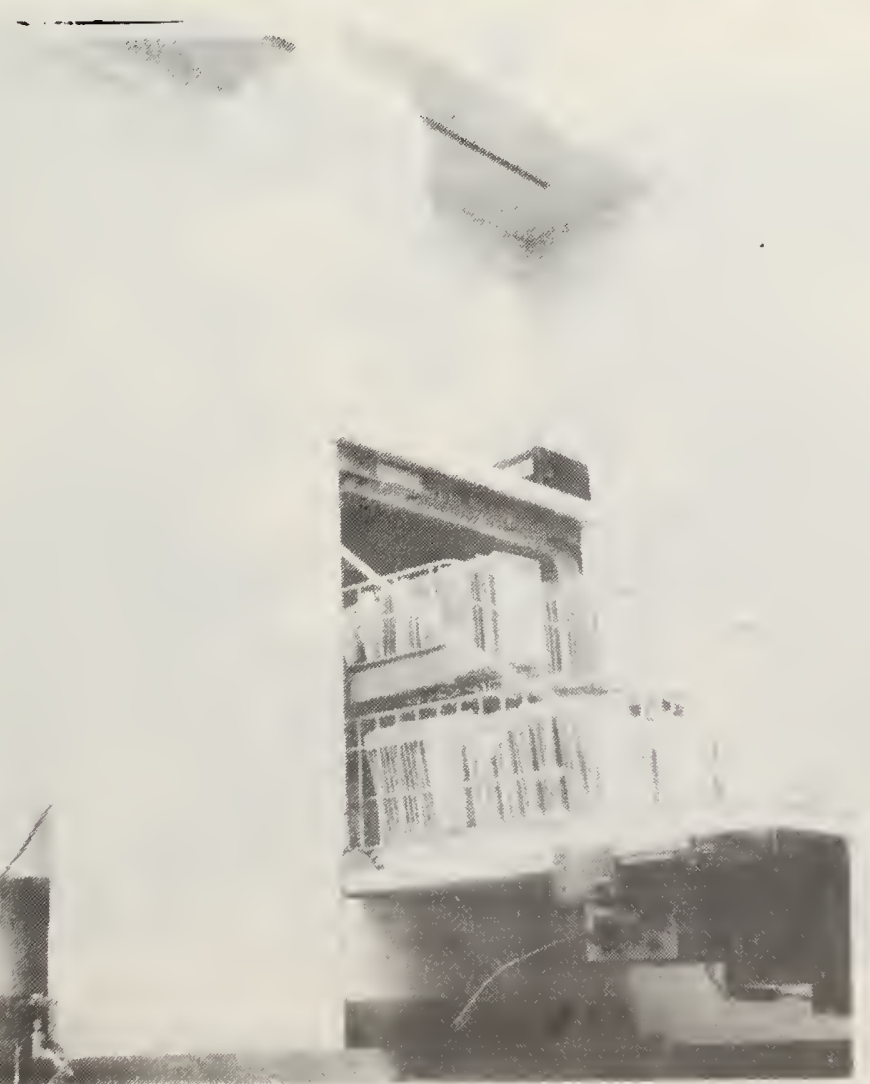

Figure 6. Accelerated bath cycle apparatus - panels loaded in rack 


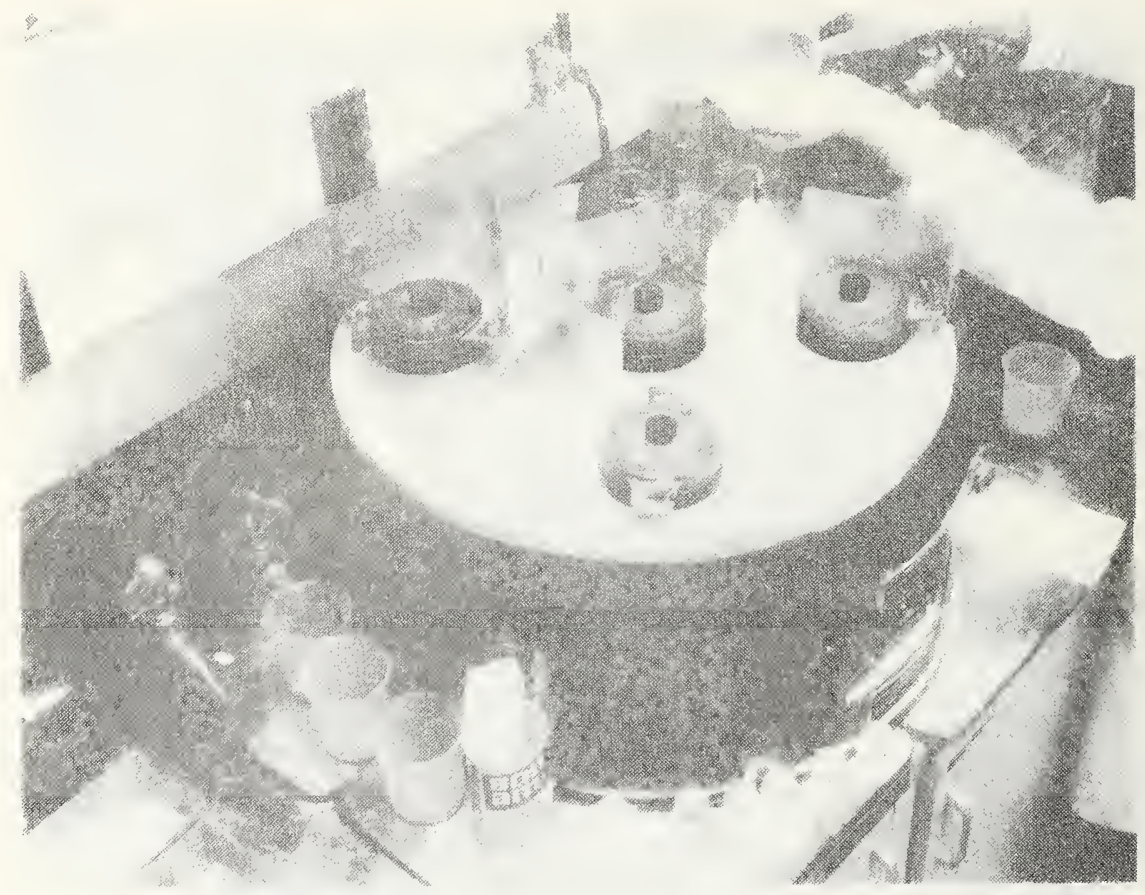

Figure 7. Modified abrasion procedure using PEI abrasion tester and alloy balls

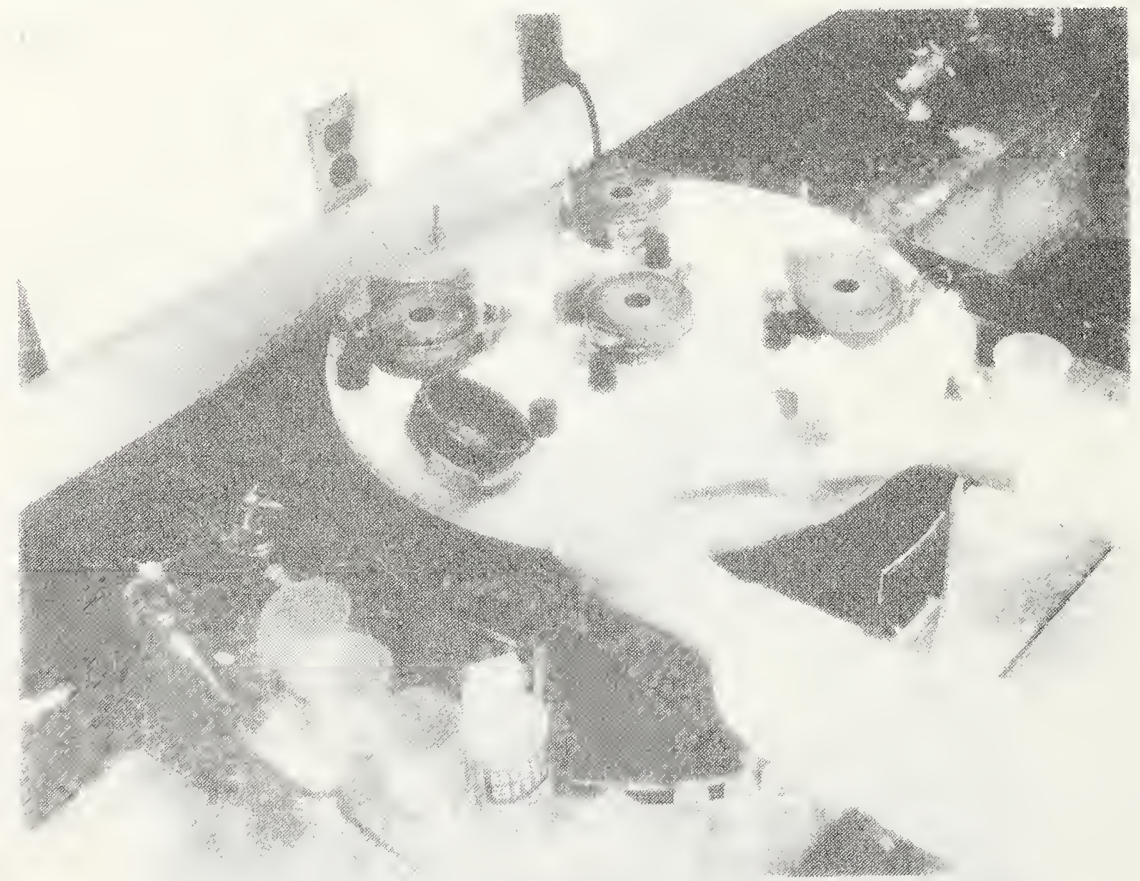

Figure 8. Modified abrasion procedure - placing test panels on apparatus 


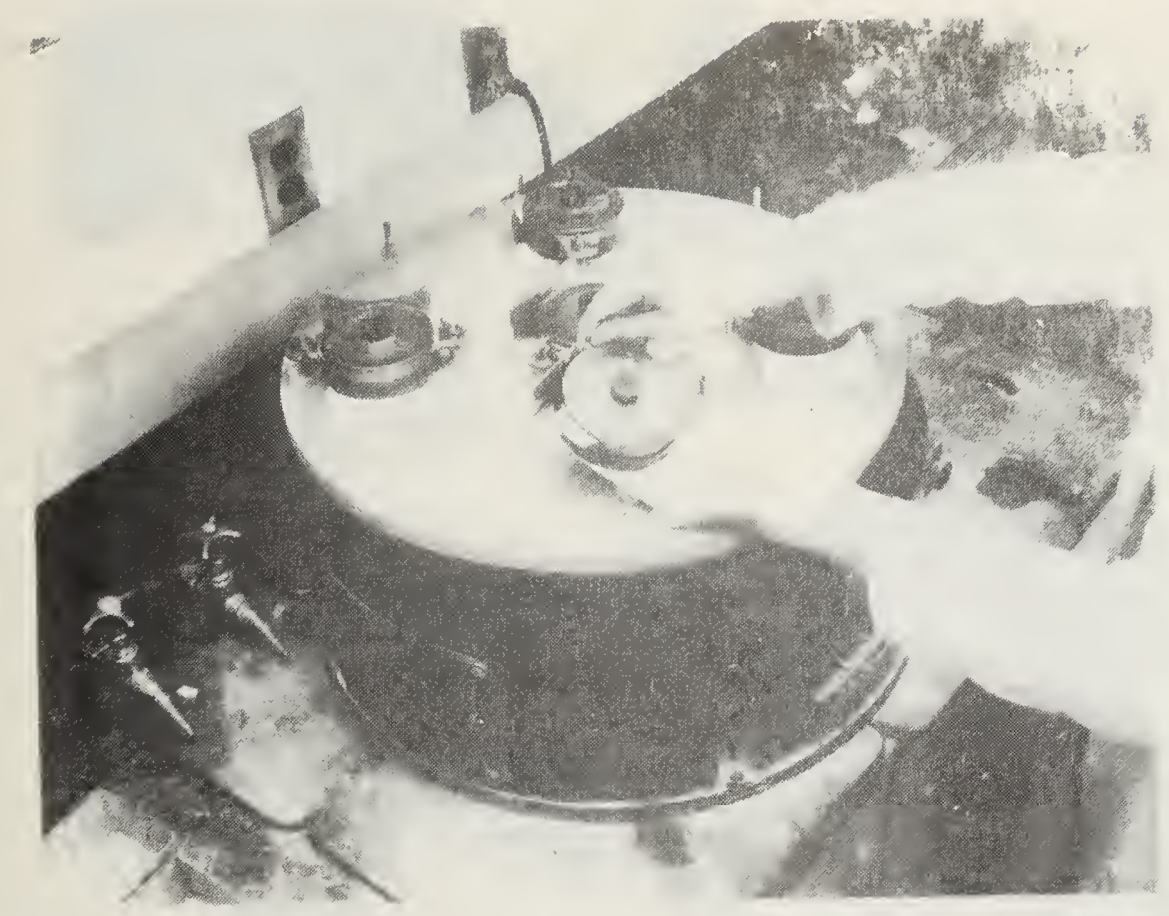

Figure 9. Modified abrasion procedure - placing containers for holding alloy balls and abrasive on test panels

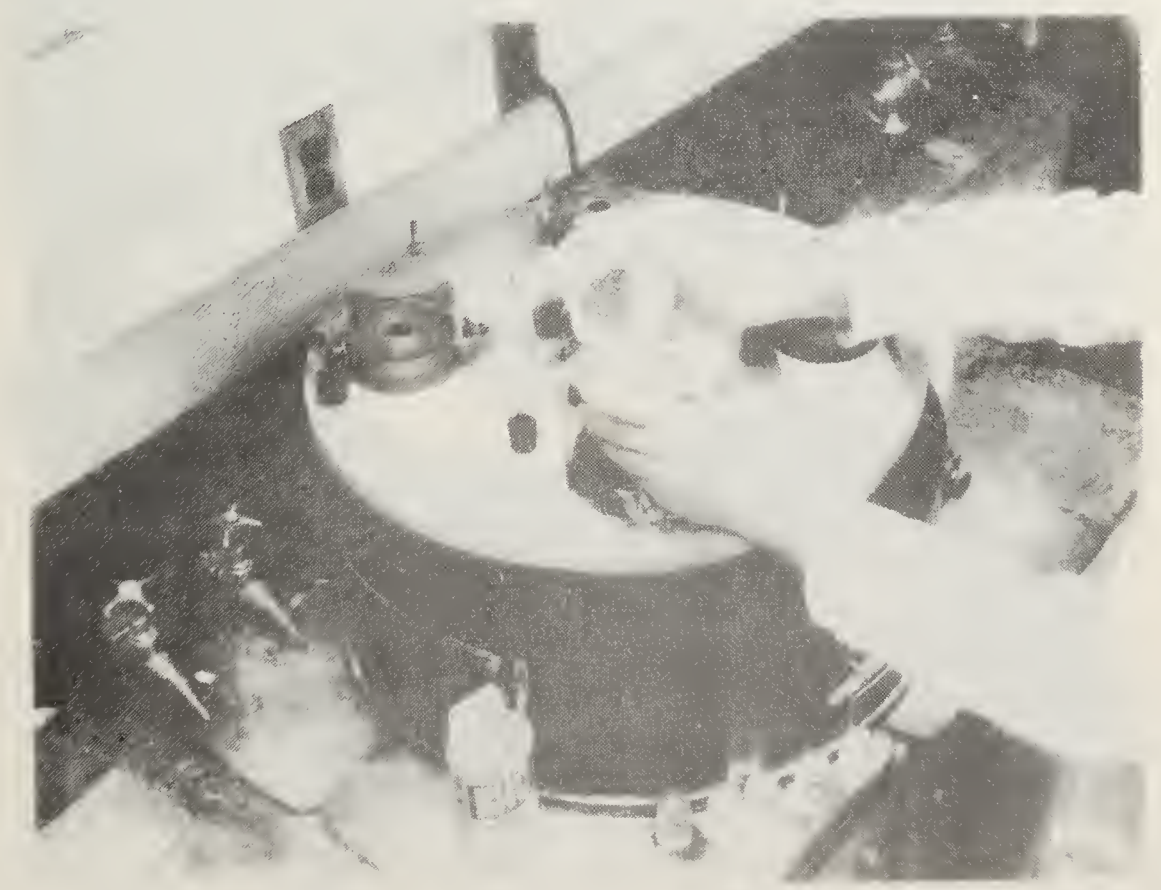

Figure 10. Modified abrasion procedure - addition of alloy balls 


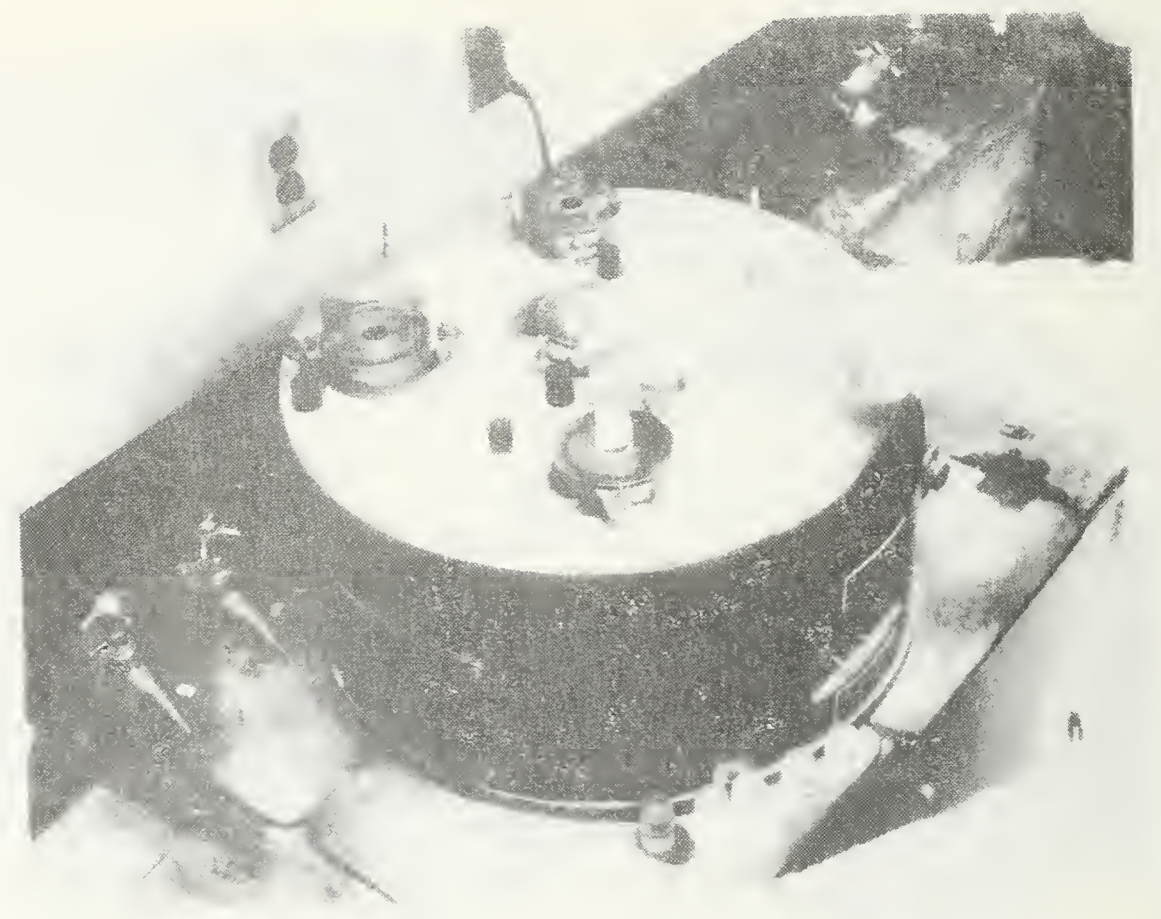

Figure 11. Modified abrasion procedure - addition of abrasive

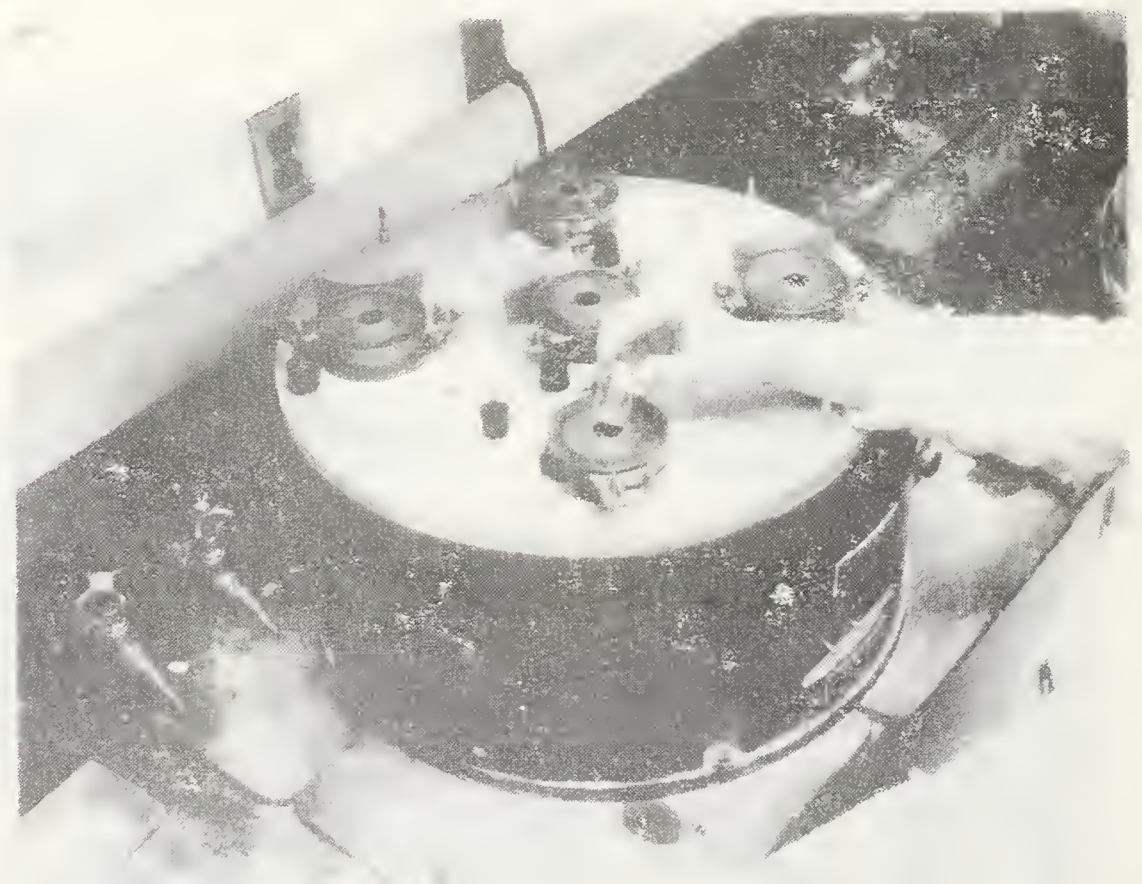

Figure 12. Modified abrasion procedure - addition of water 


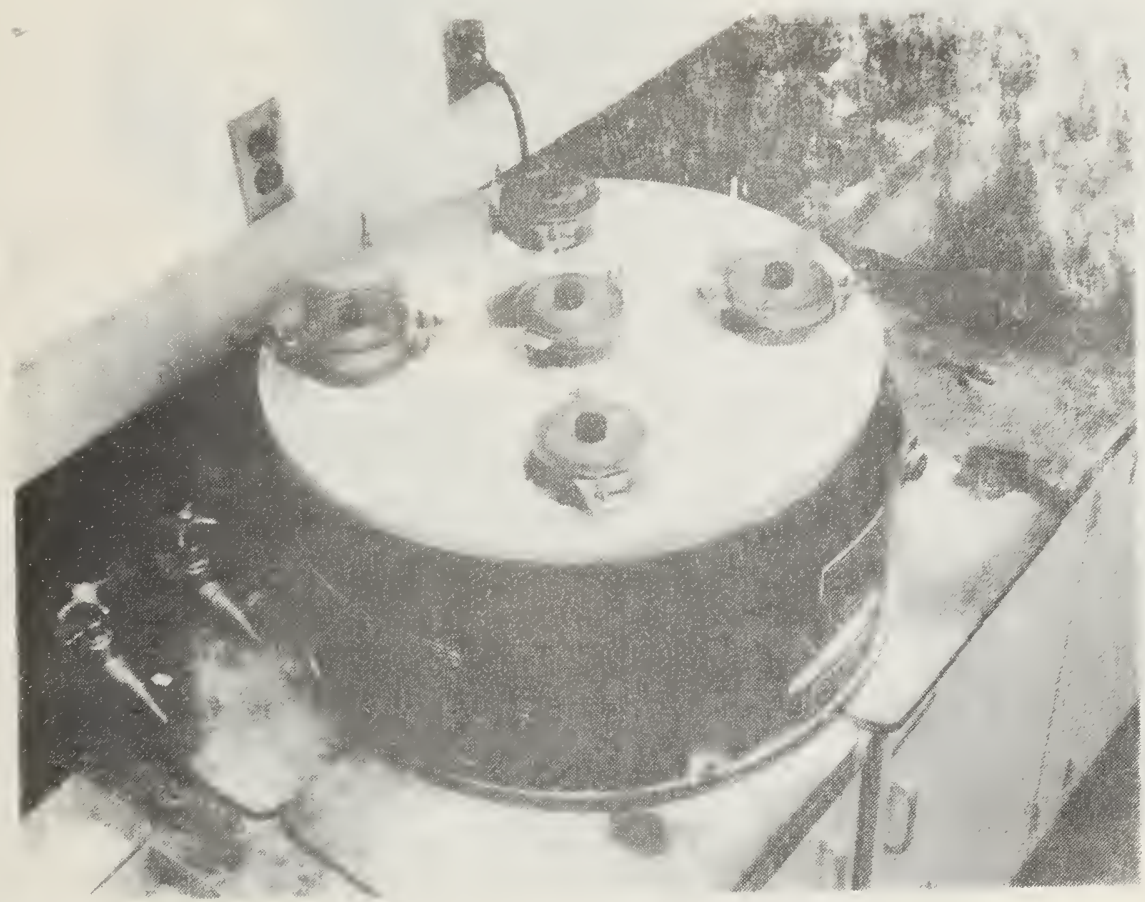

Figure 13. Modified abrasion procedure - abrasion test commences

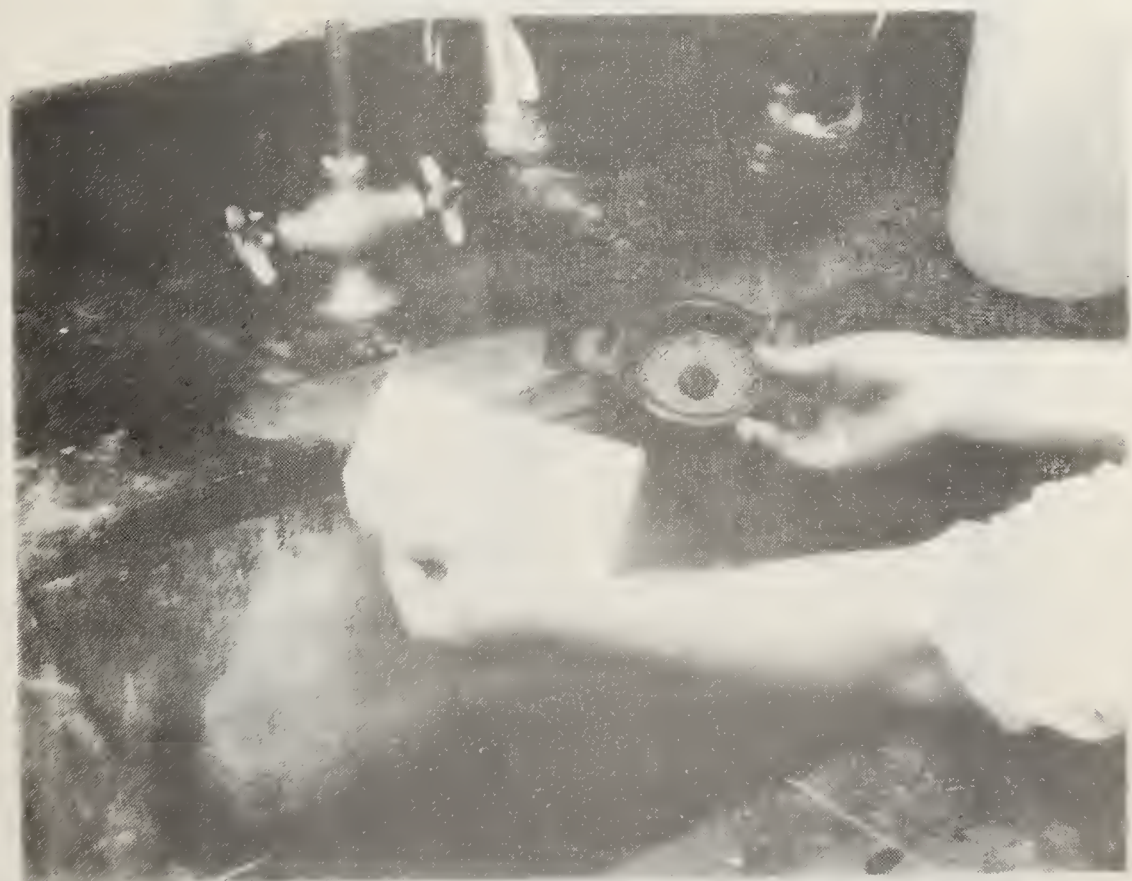

Figure 14. Modified abrasion procedure - removal of test panels and alloy balls after test 


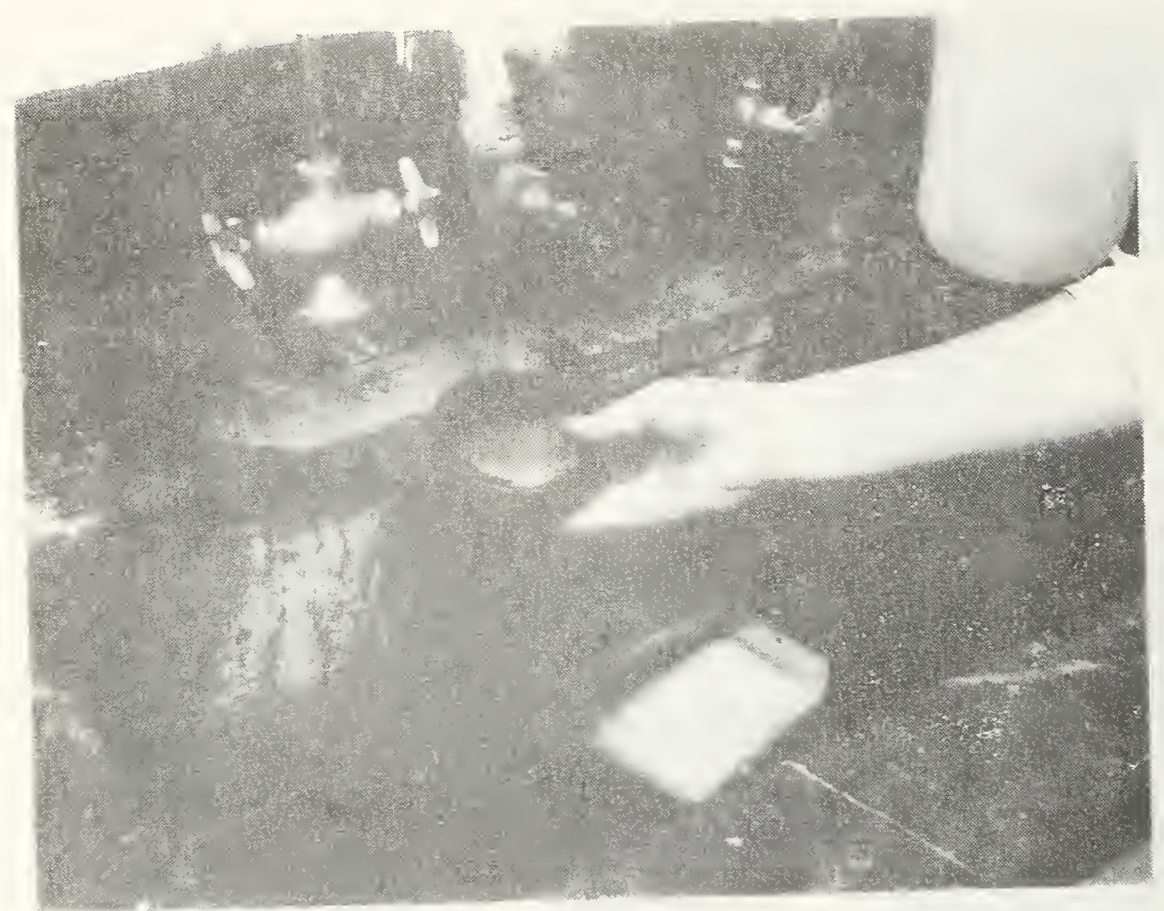

Figure 15. Modified abrasion procedure - rinsing alloy balls and test panels

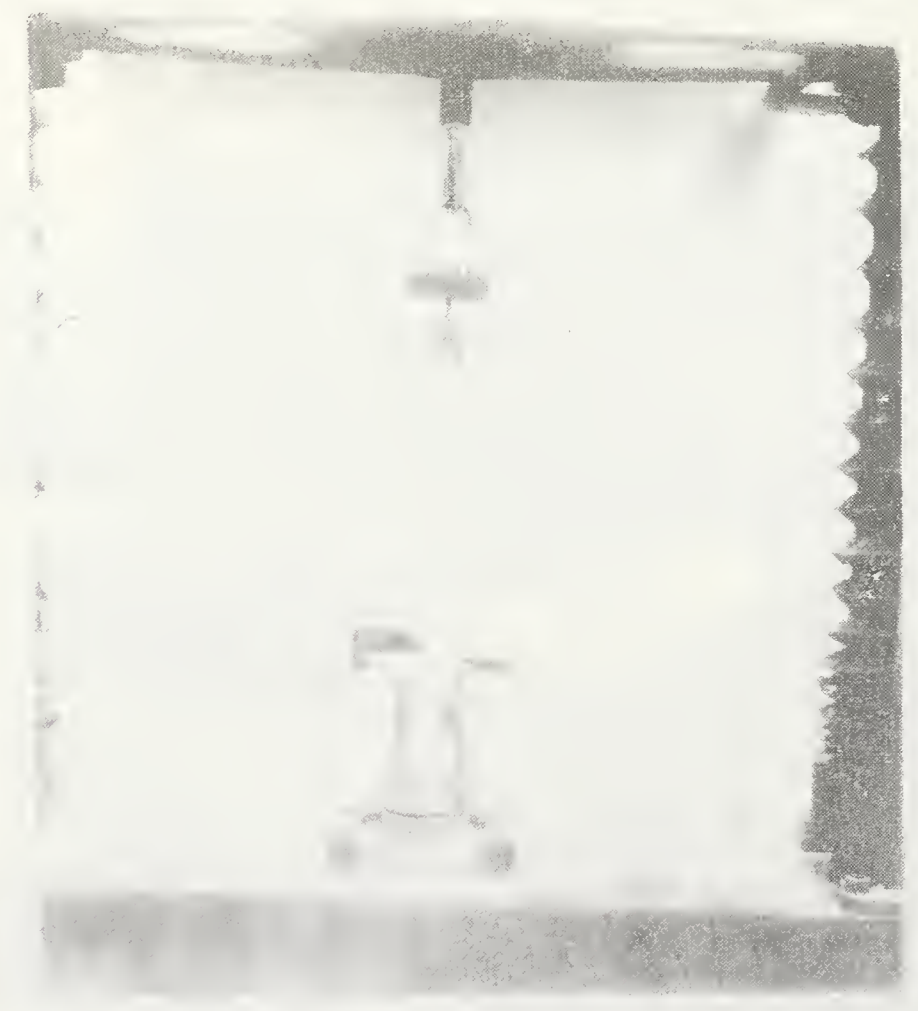

Figure 16. Adhesion procedure - yoke apparatus mounted in testing machine 


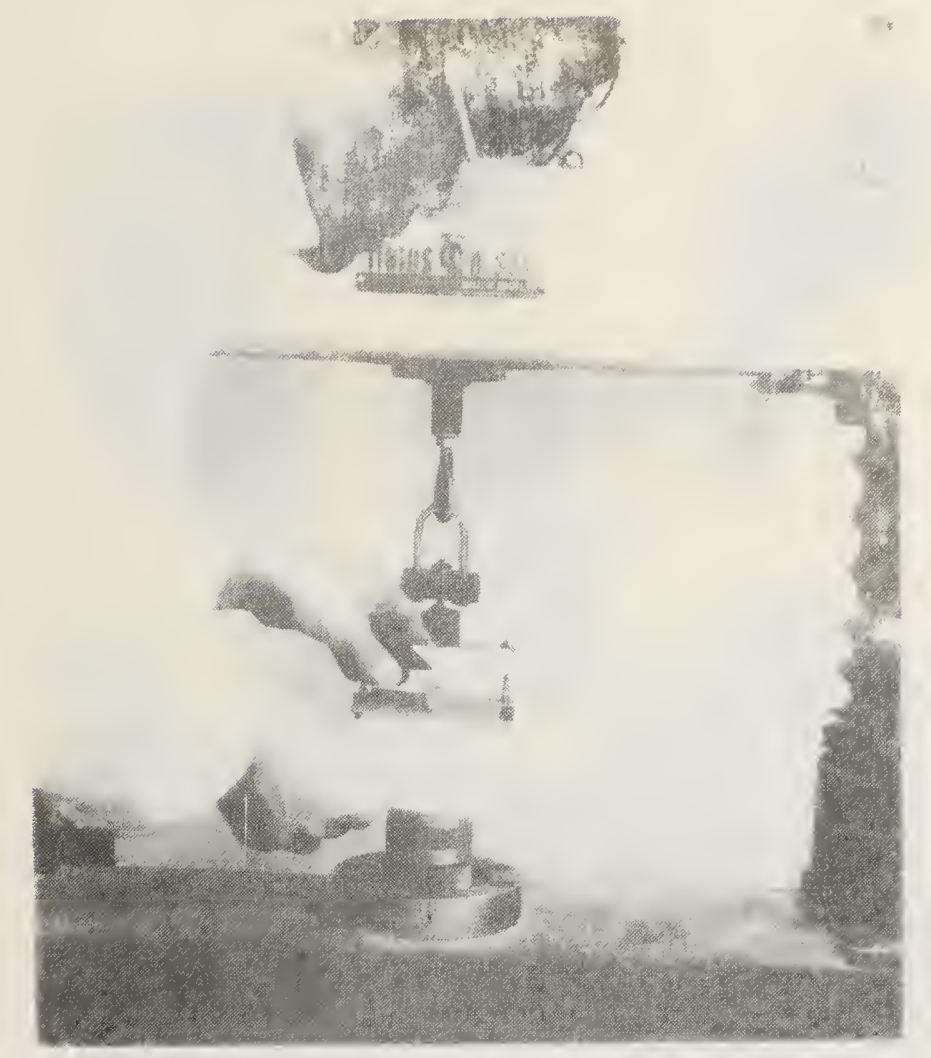

Figure 17. Adhesion procedure - insertion of test panel with buttons attached

sar
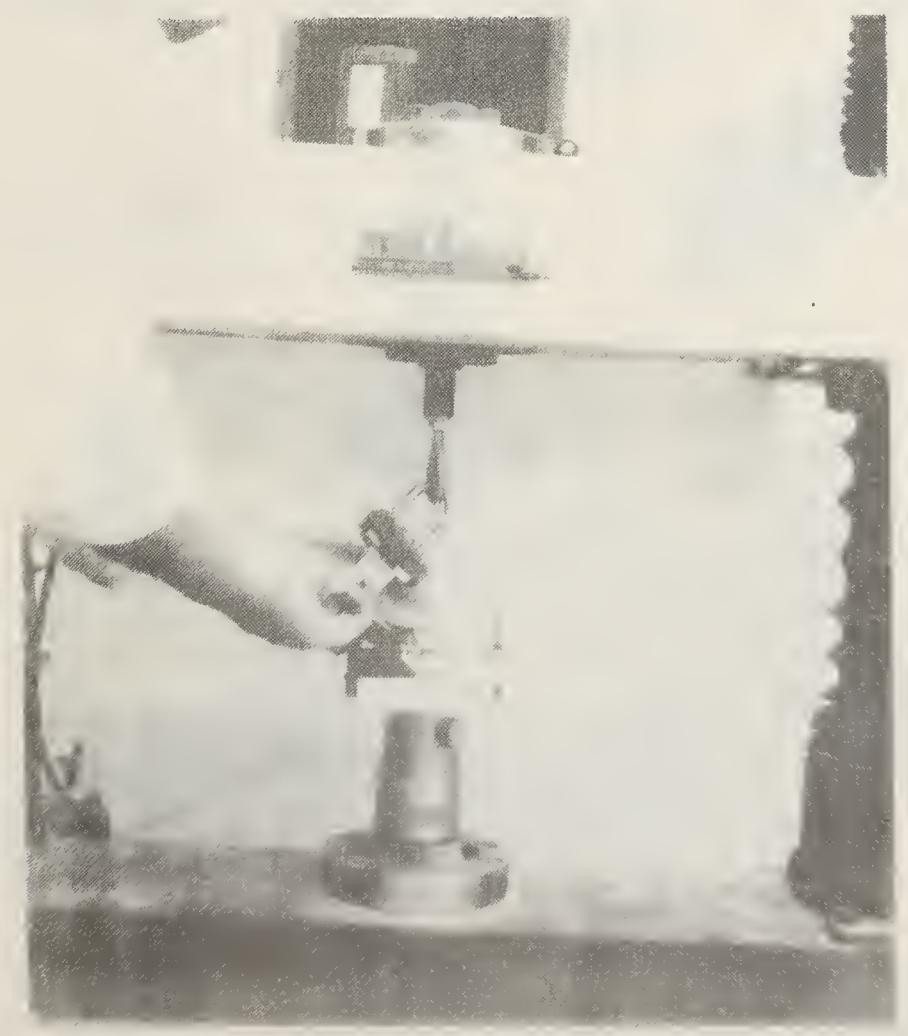

Figure 18. Adhesion procedure - joining upper and lower portions of yoke apparatus 


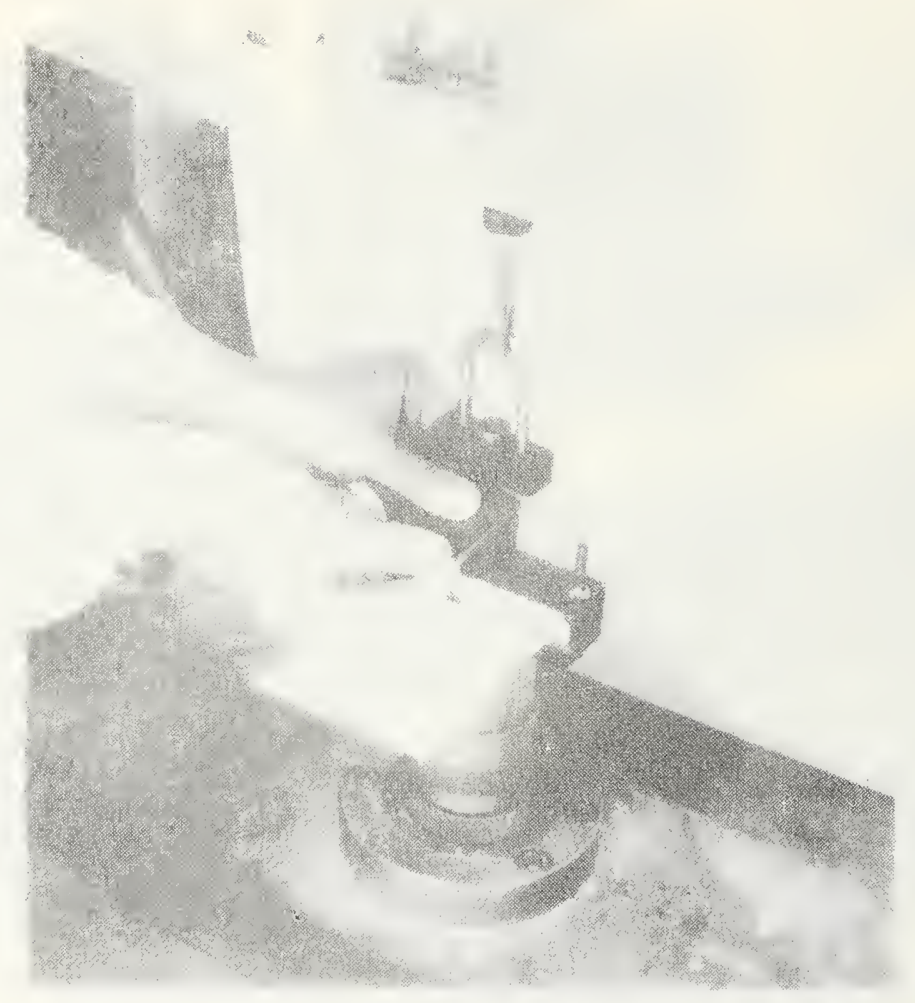

Figure 19. Adhesion procedure - joining upper and lower portions of yoke apparatus

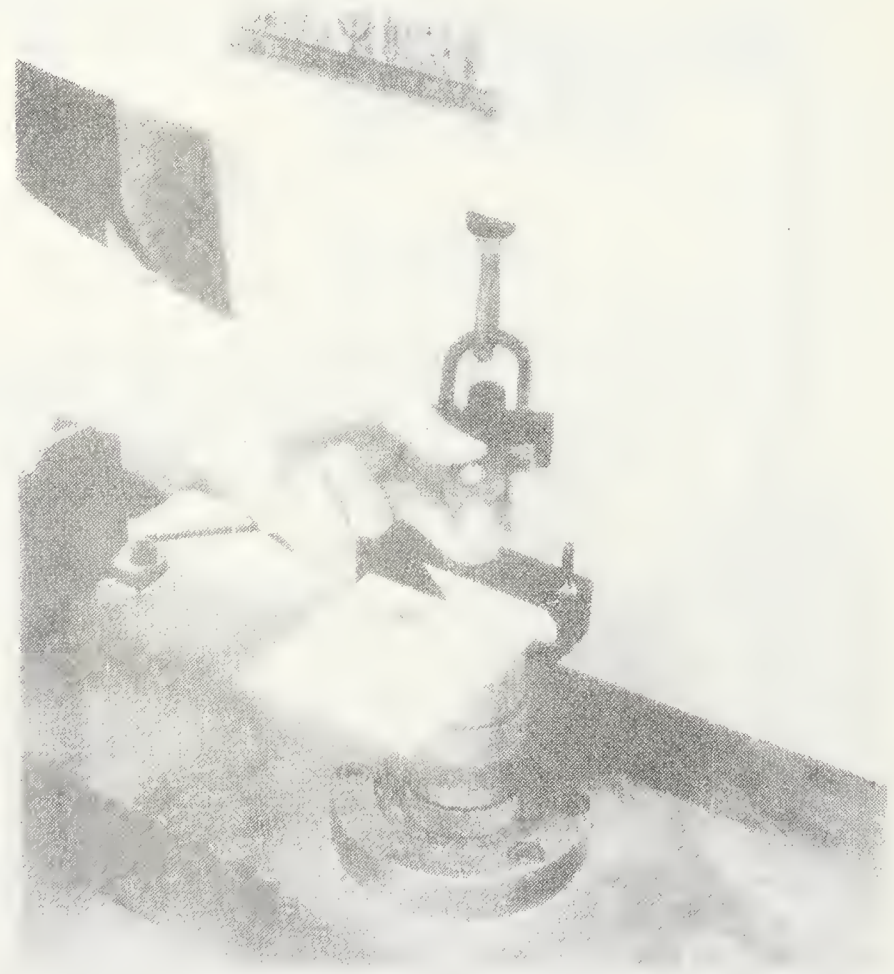

Figure 20. Adhesion procedure - after test, bottom of button showing delaminated coating 


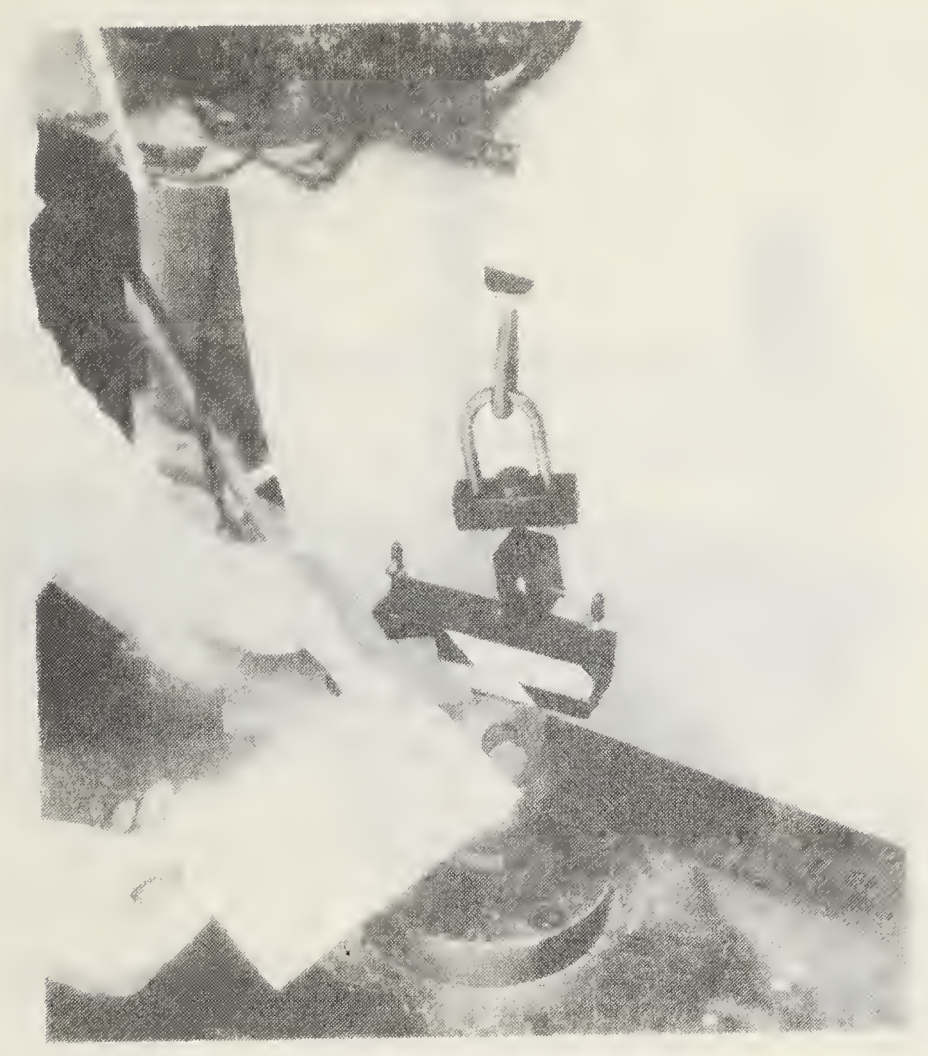

Figure 21. Adhesion procedure - coated area pulled off after testing

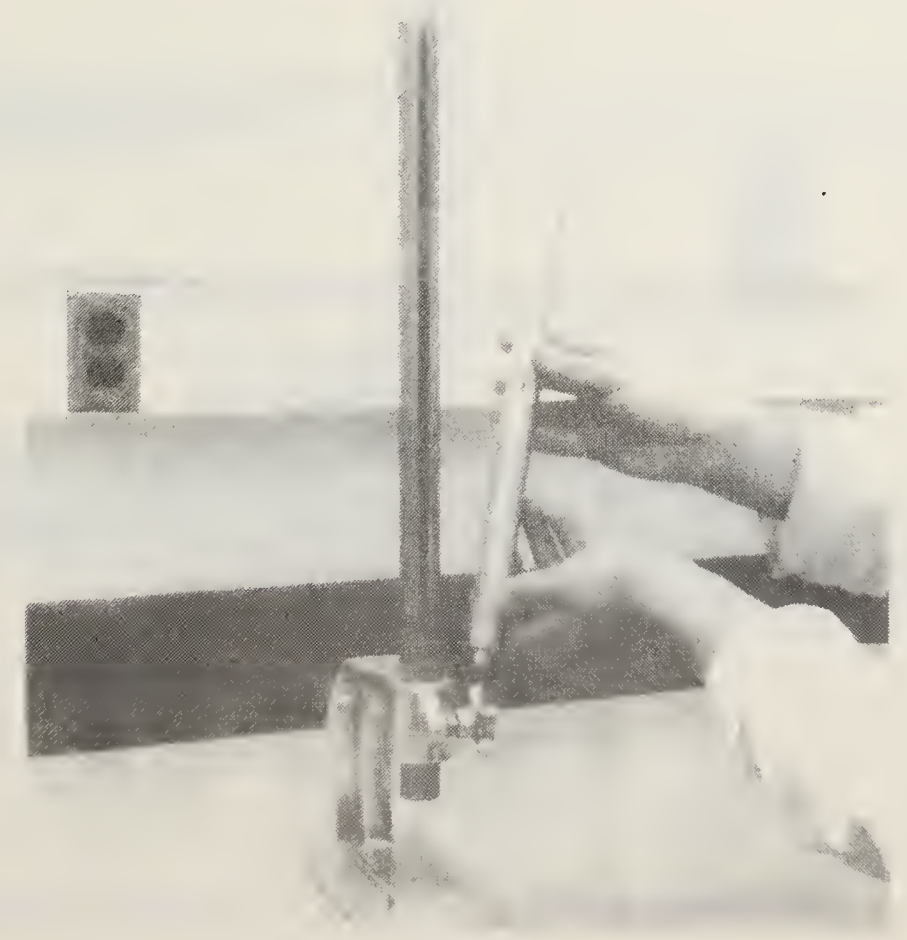

Figure 22. Inpact resistance procedure - apparatus with aluminum impactor cylinder 


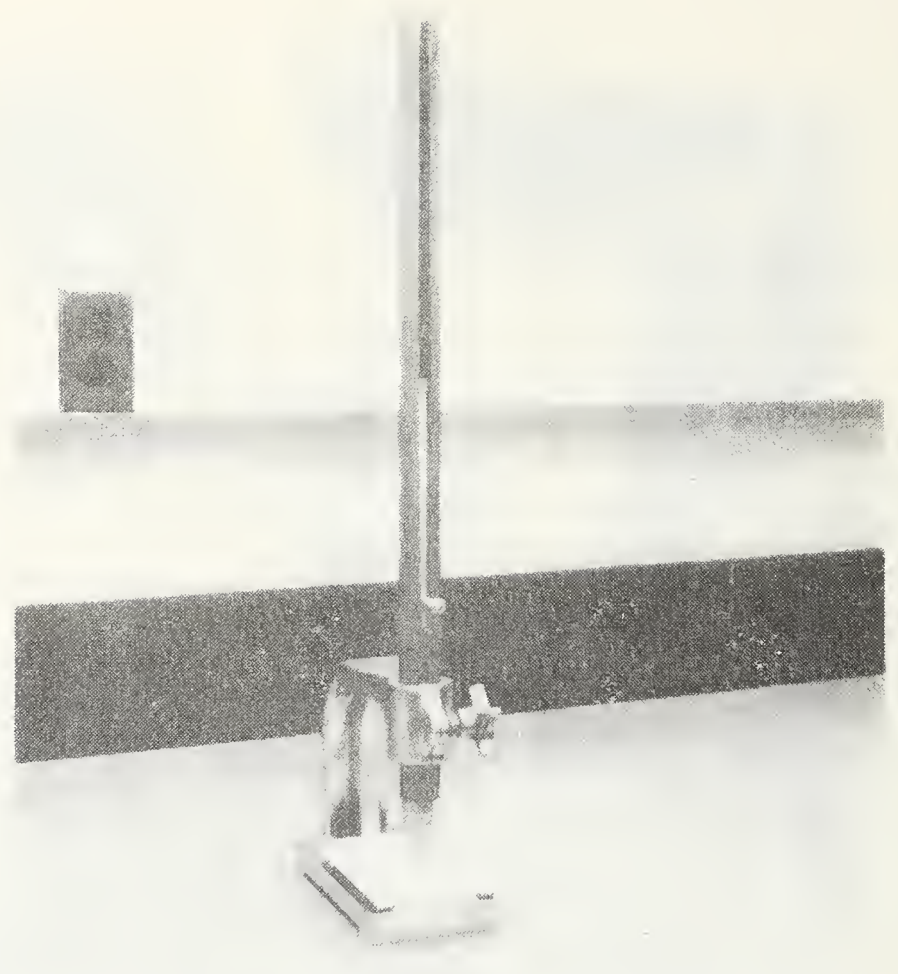

Figure 23. Impact resistance procedure - apparatus with test panel in place

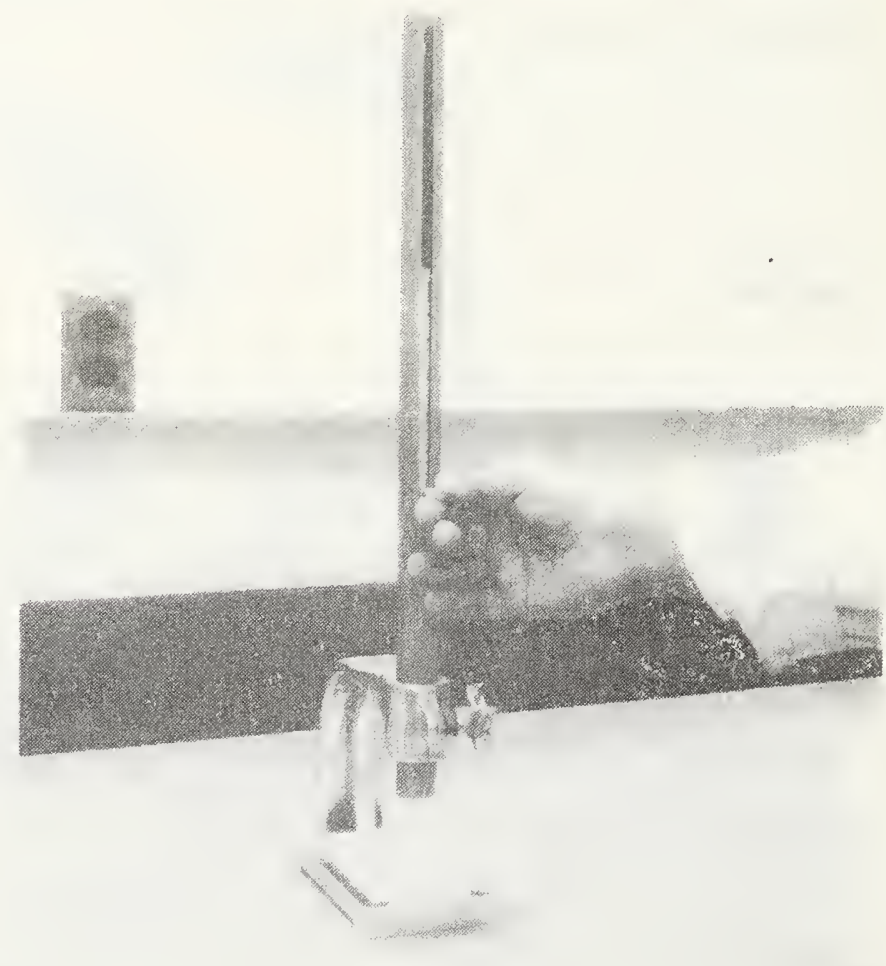

Figure 24. Impact resistance procedure - raising impactor cylinder 


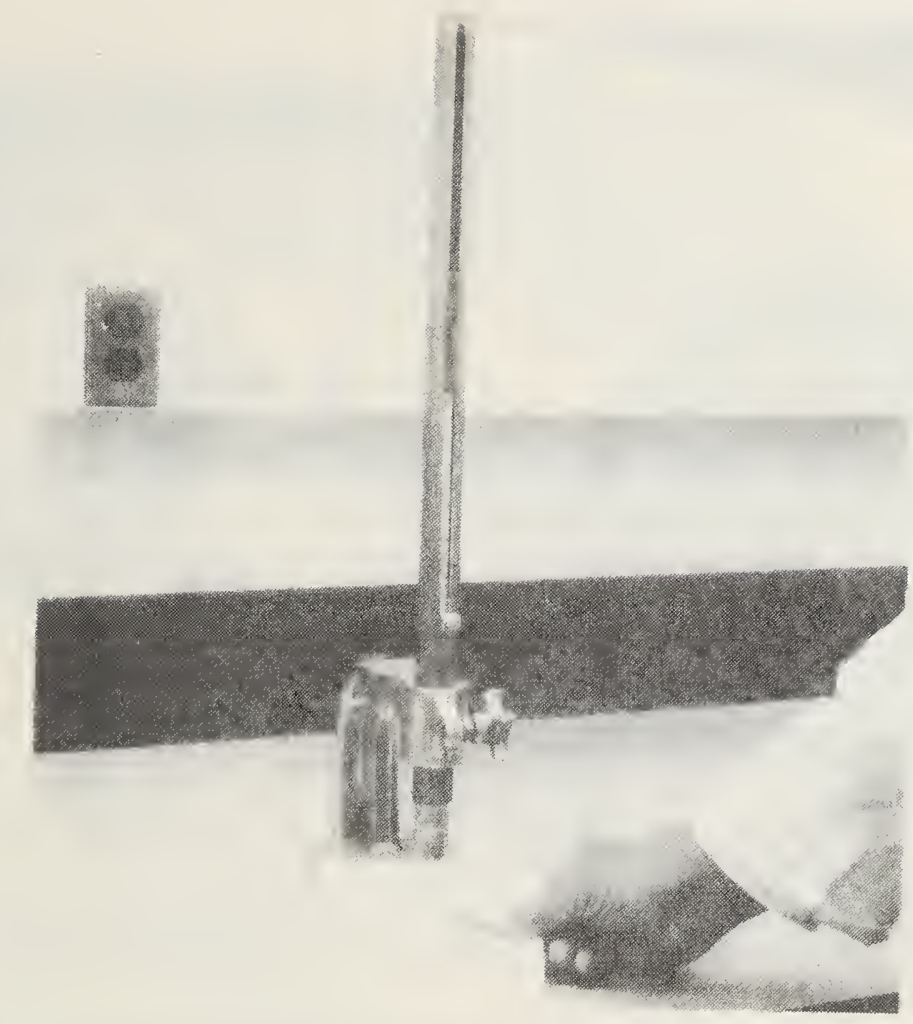

Figure 25. Impact resistance procedure - test panel after impact
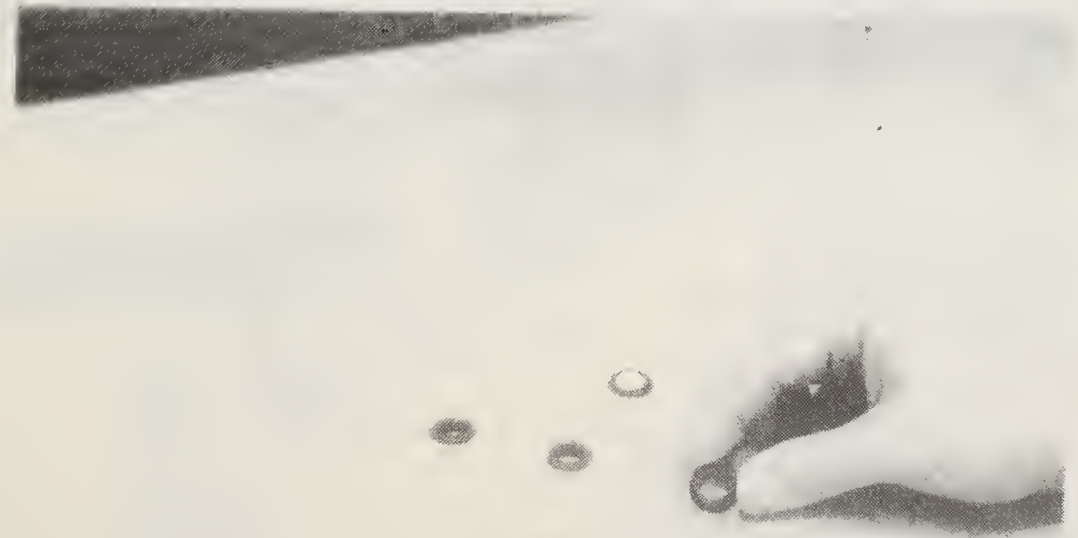

Figure 26. Stain resistance test procedure - chambers with rubber seals 


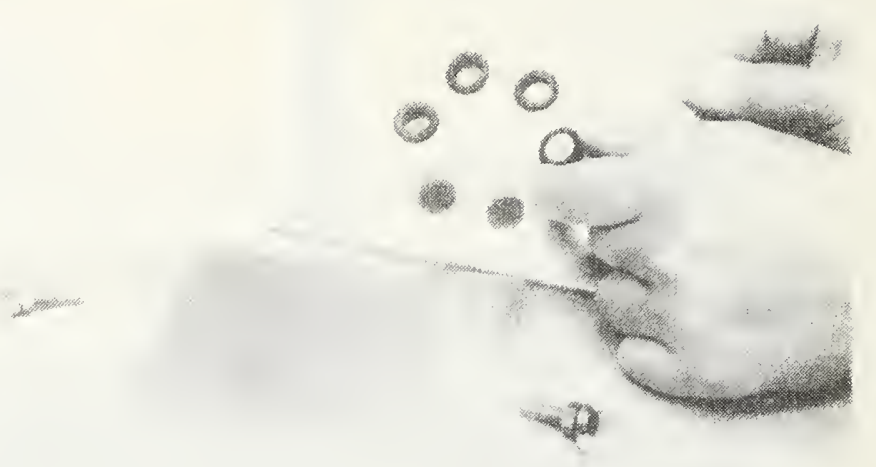

Figure 27. Stain resistance test procedure - chambers inserted in upper section of holder

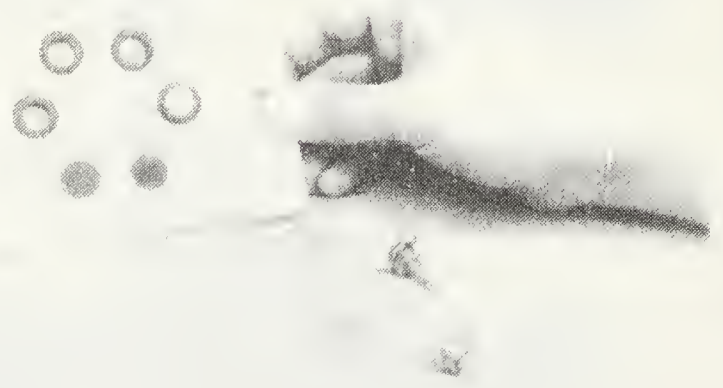

Figure 28. Stain resistance test procedure - upper holder prior to clamping 


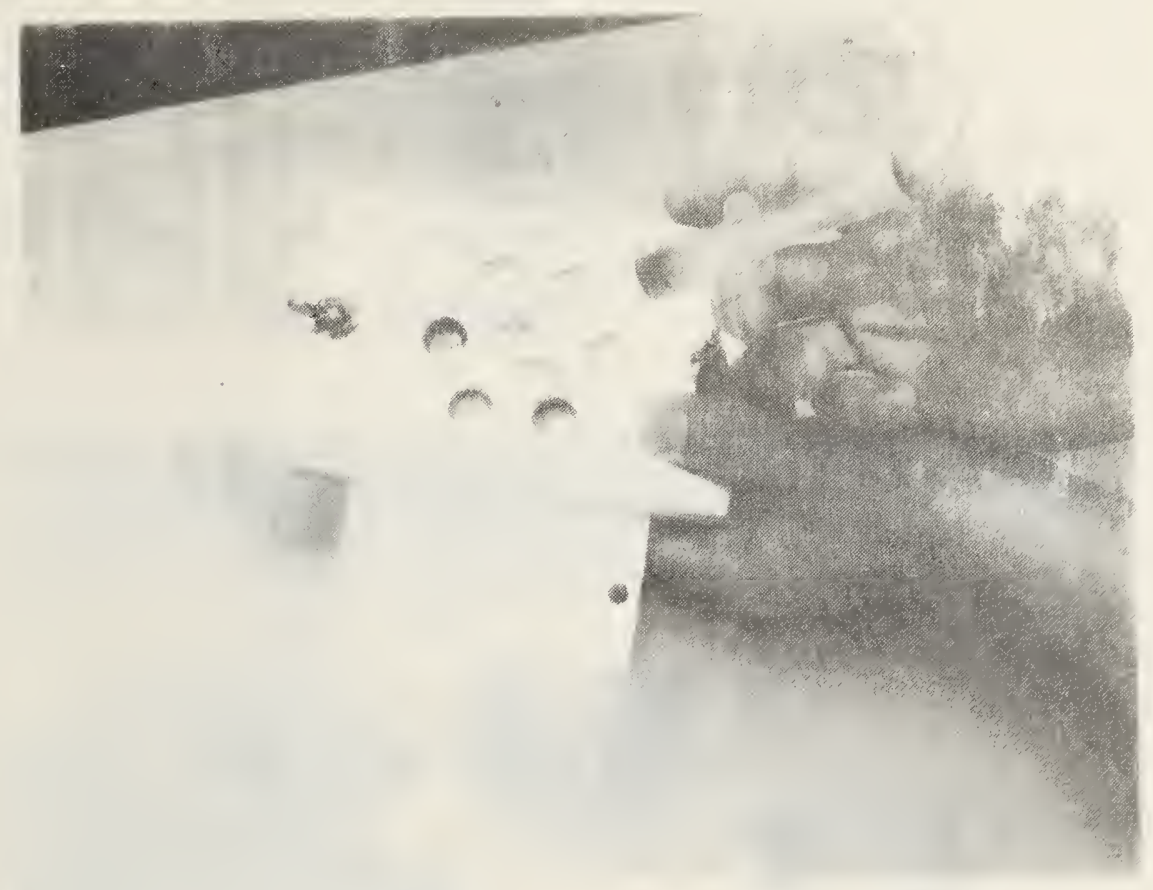

Figure 29. Stain resistance test procedure - application of liquid stain

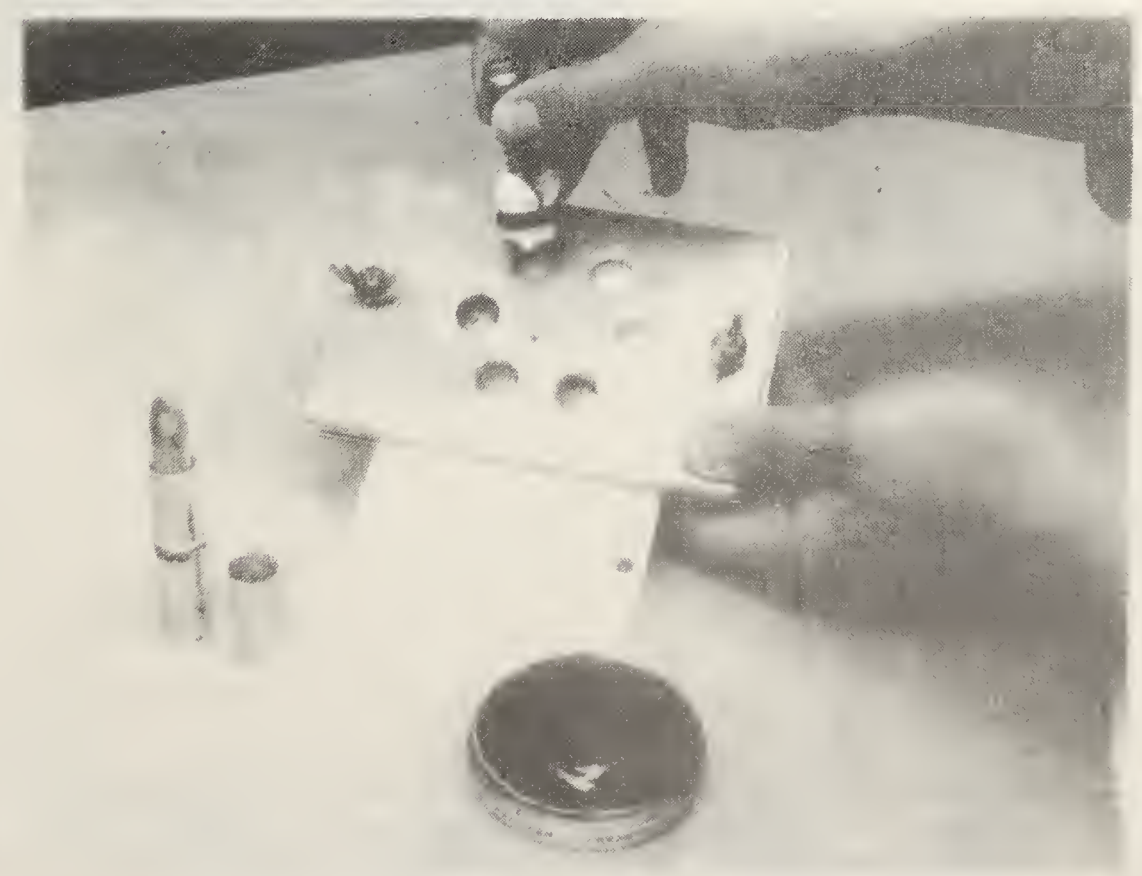

Figure 30. Stain resistance test procedure - application of solid stain 


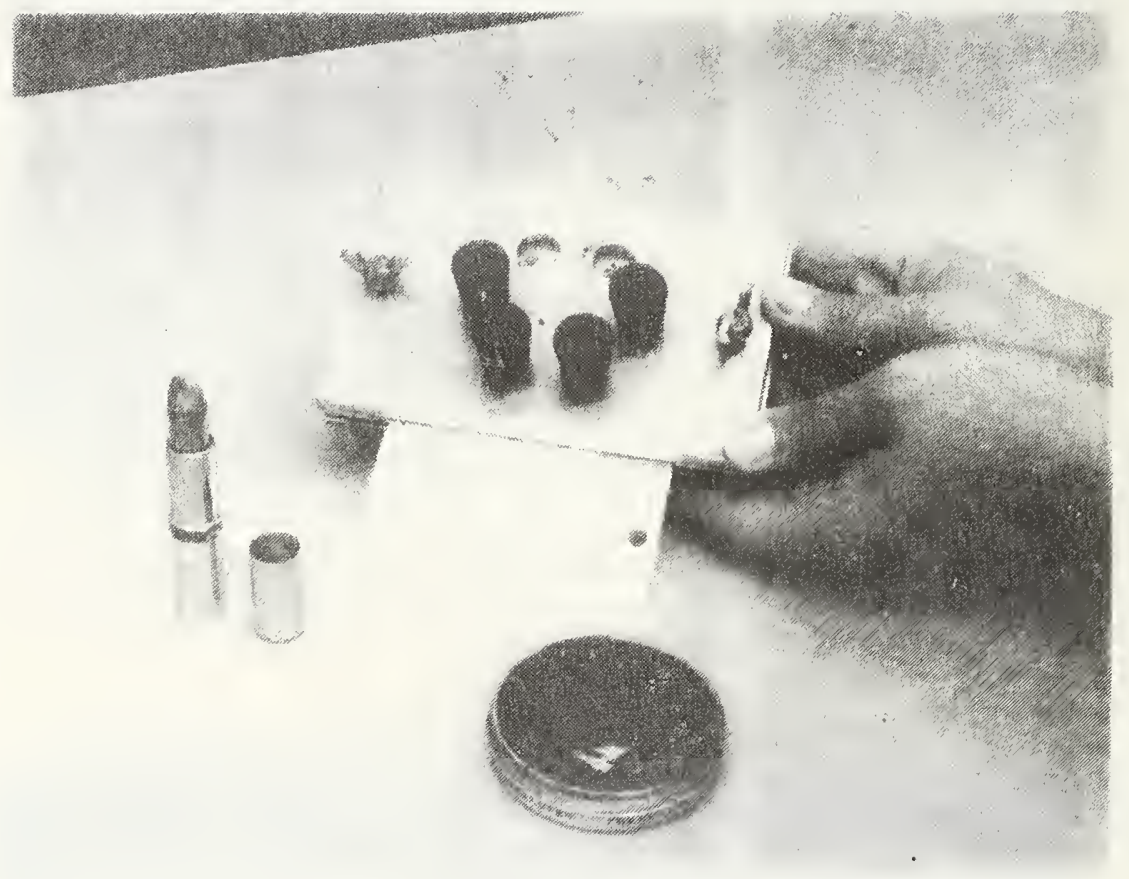

Figure 31. Stain resistance test procedure - test complete, removal of rubber seals 


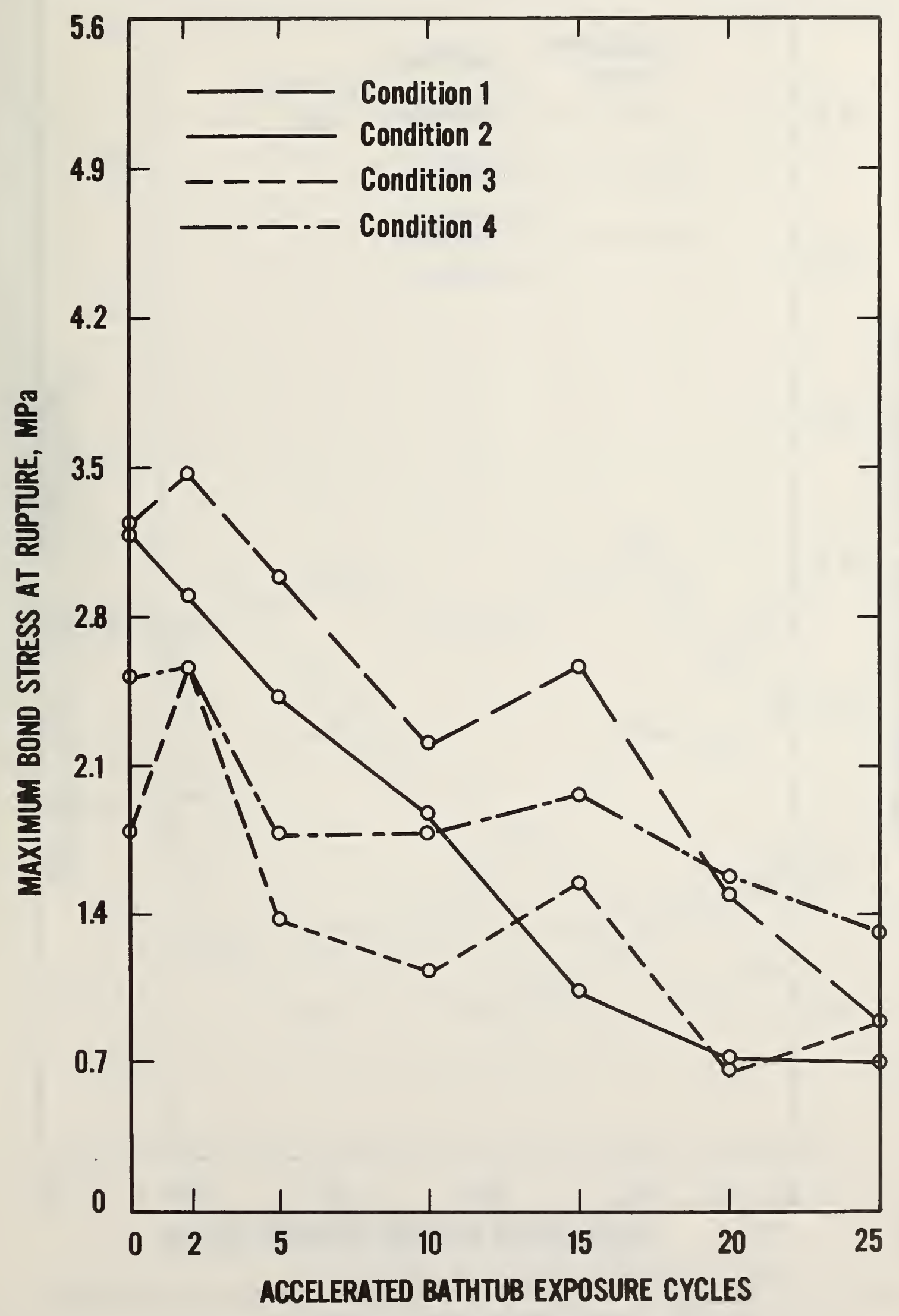

igure 32. Average stress at rupture for various accelerated bathtub exposure cycles (Restoration Coating 1) 


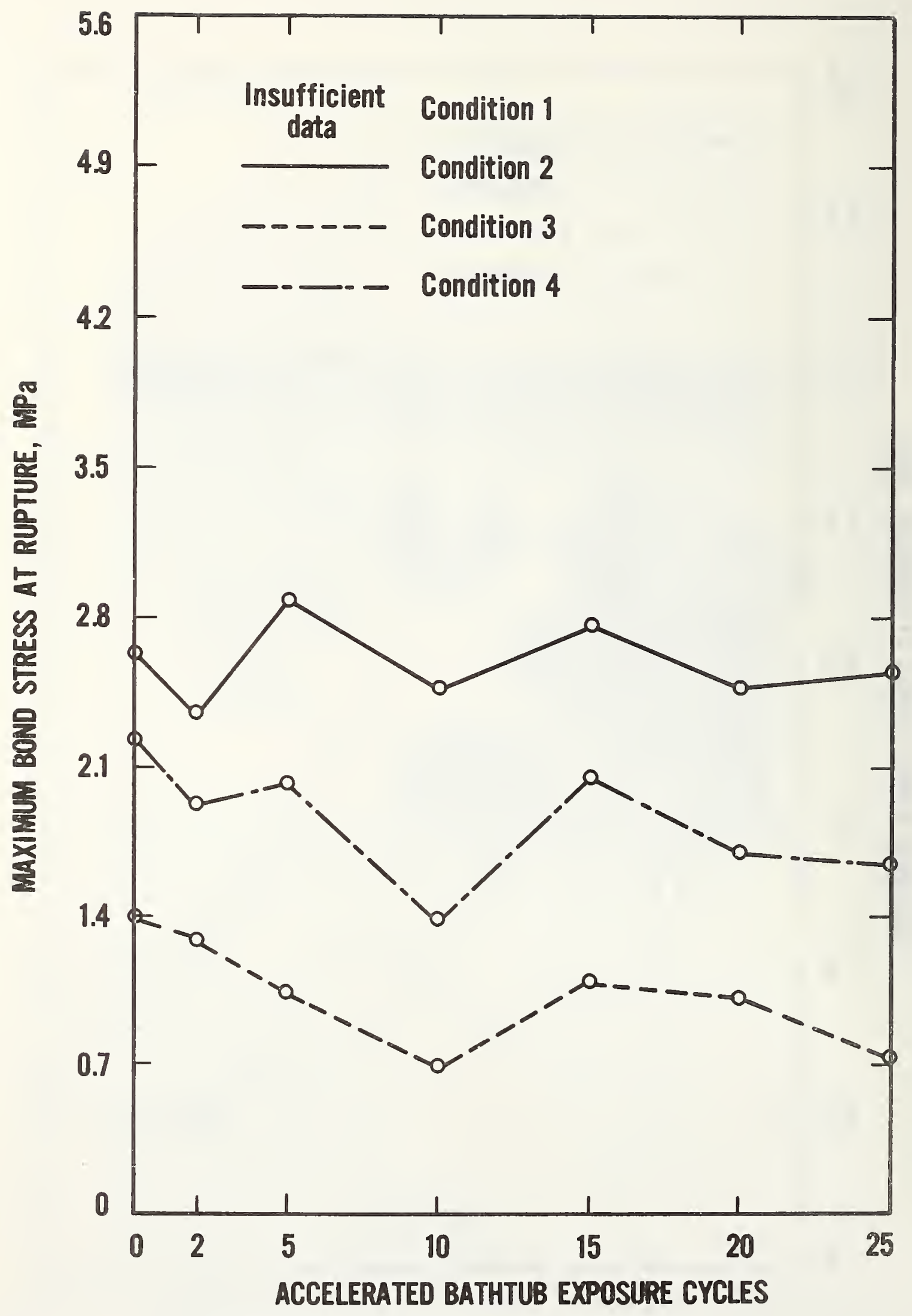

kigure 33. Average stress at rupture for various accelerated bathtub exposure cycles (Restoration Coating 2) 


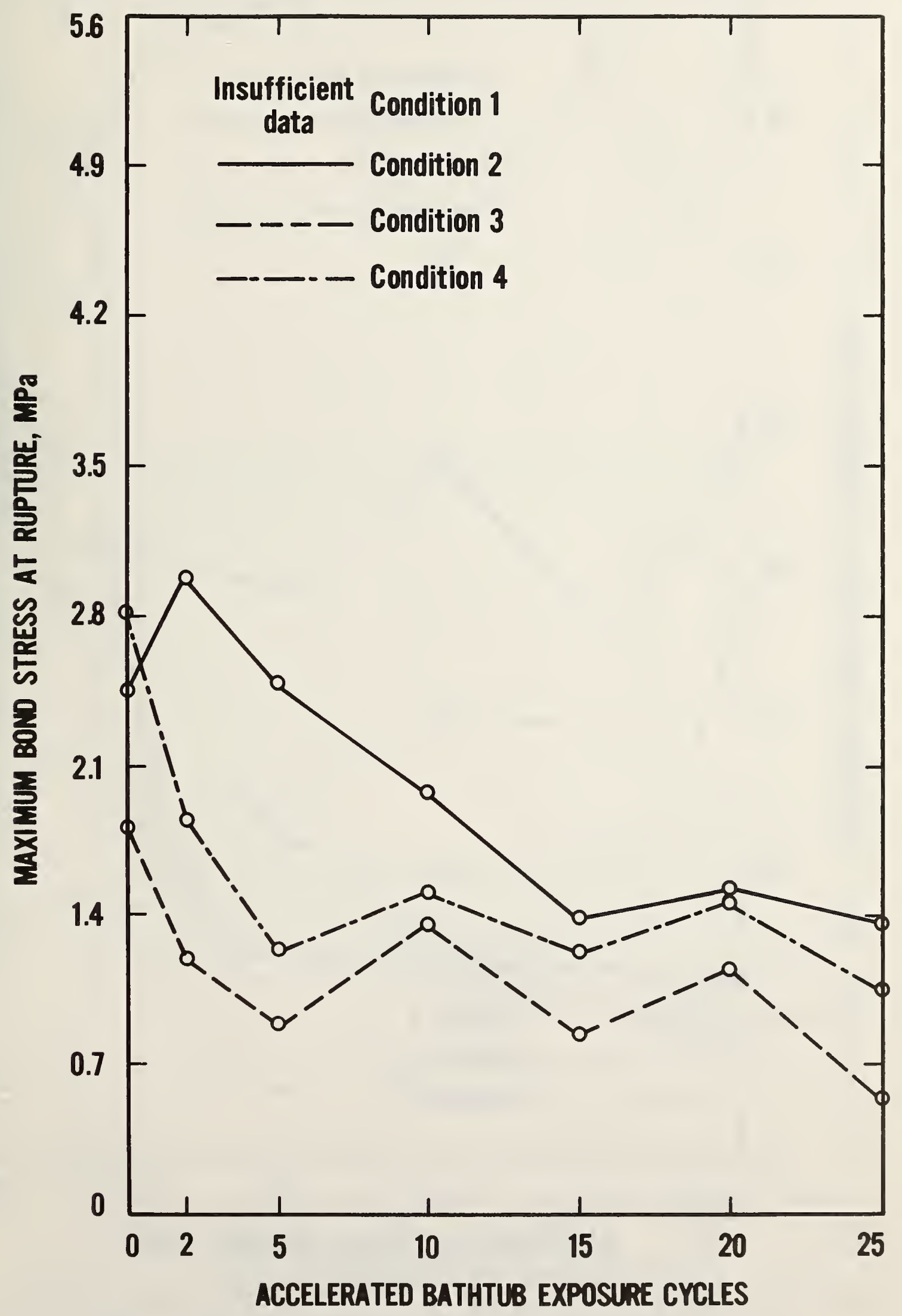

Figure 34. Average stress at rupture for various accelerated bathtub exposure cycles (Restoration Coating 3 ) 


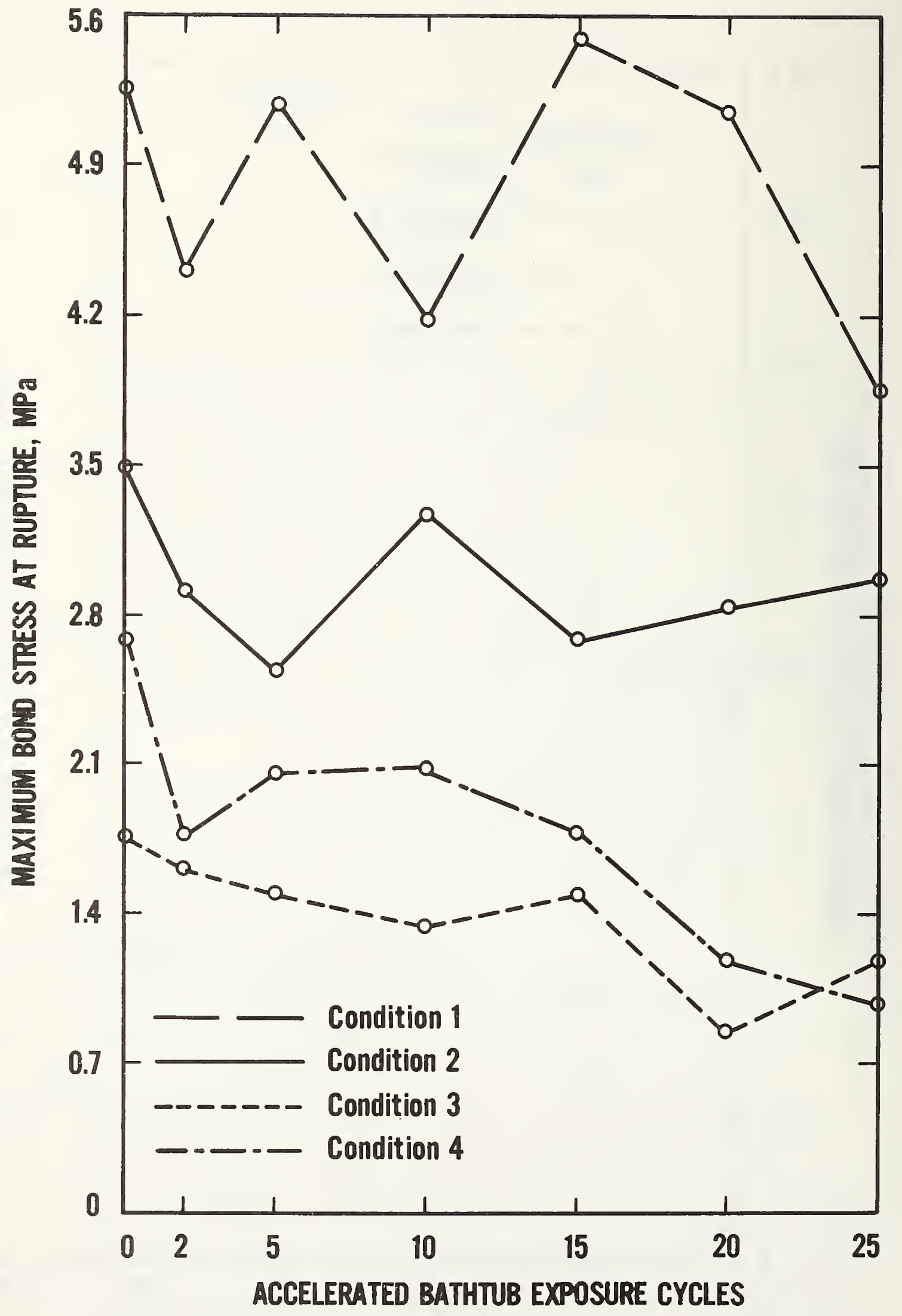

Figure 35. Average stress at rupture for various accelerated bathtub exposure cycles (Restoration Coating 4) 


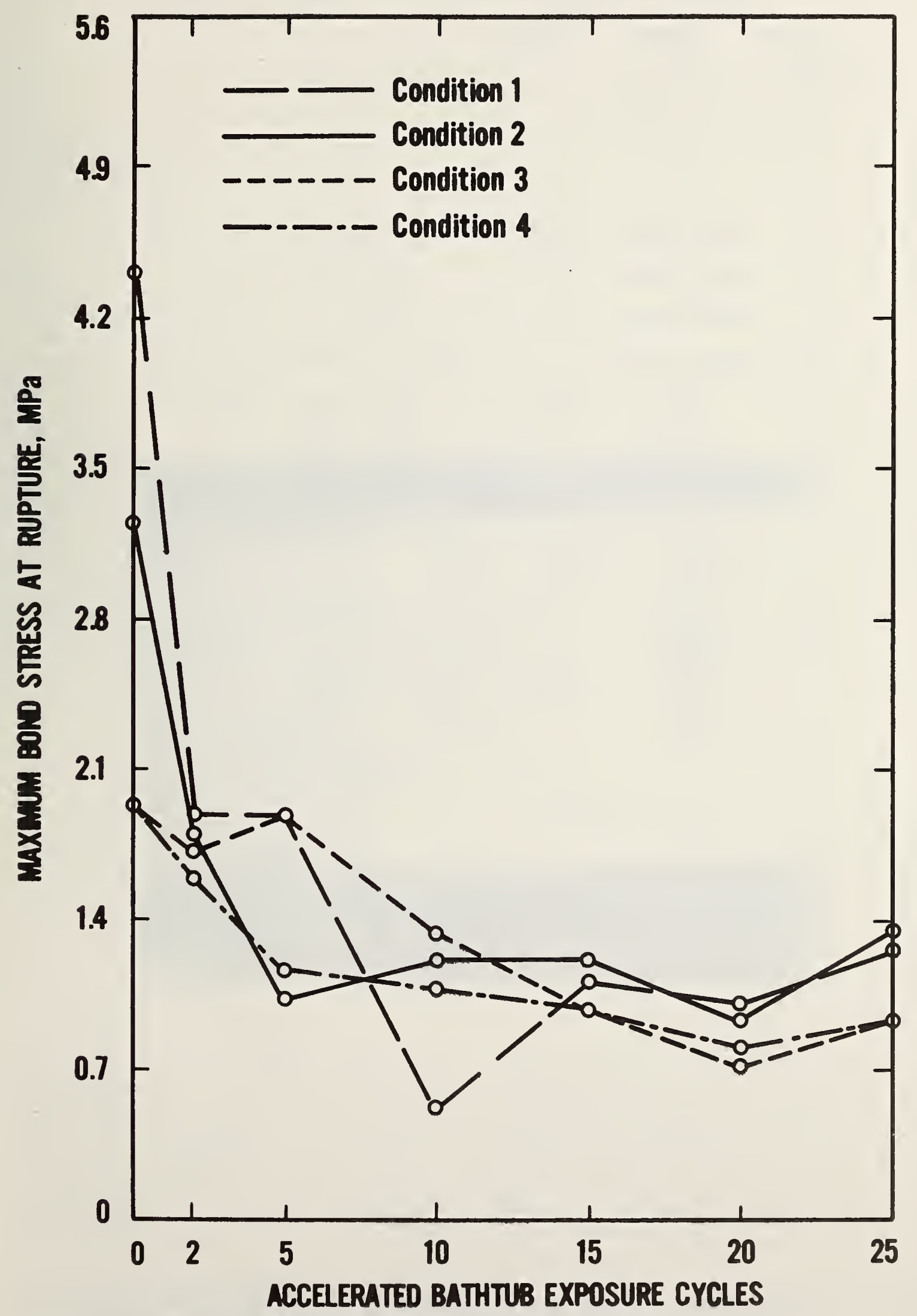

Figure 36. Average stress at rupture for various accelerated bathtub exposure cycles (Restoration Coating 5) 


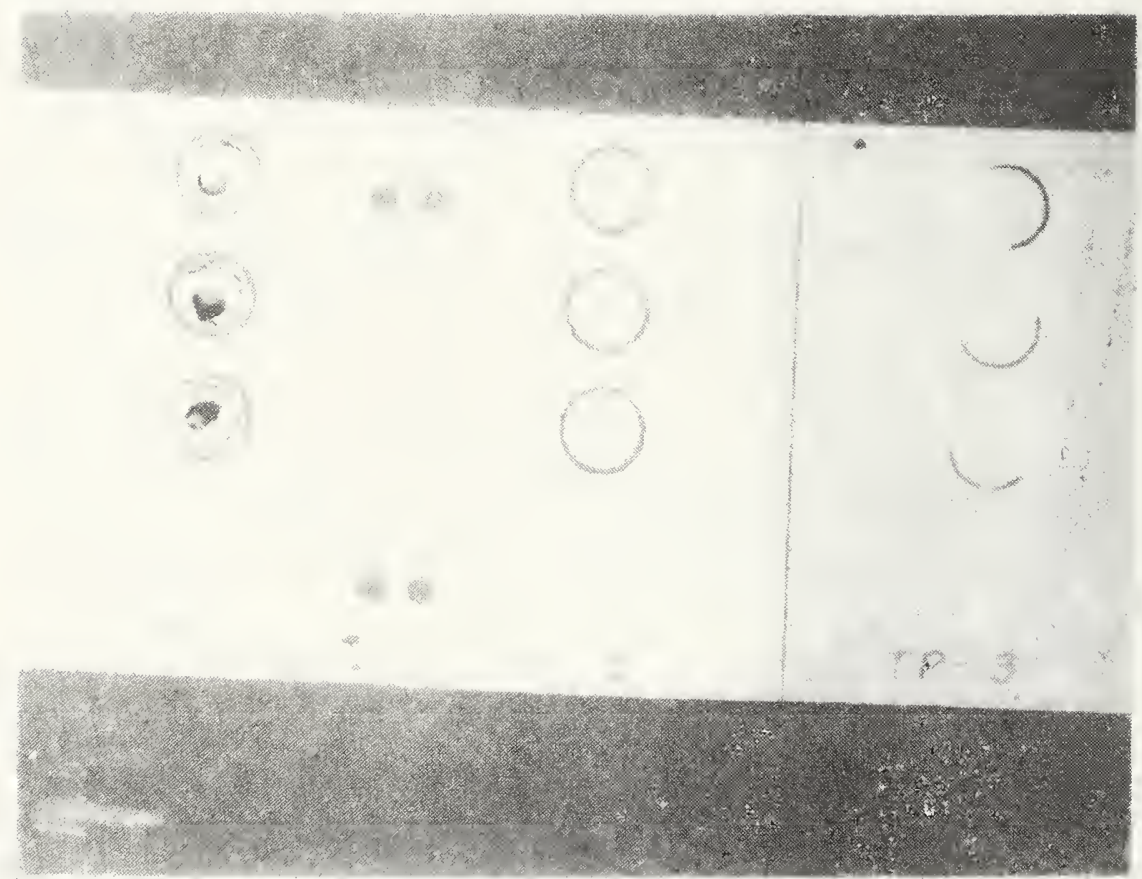

Figure 37. Restoration coating 5 after adhesion tests; left panel unexposed, center panel after two ABECs; right panel after three ABECs 
Appendix A. Commercially Avallable Restoration Coatings //

\begin{tabular}{lccc} 
Company Name & Types of Repalrs & $\begin{array}{c}\text { Surface } \\
\text { Preparation Finishes }\end{array}$ & $\begin{array}{c}\text { Cost of } \\
\text { Refinishing } \\
(\$)\end{array}$ \\
\hline
\end{tabular}

$\mathrm{Nu}-\mathrm{Glaze}$

Perma-Patch Inc.

Lik-Nu Porcelain Inc.

Dyna-Glaze Co.

Authorized SPR

Tub Reglazing

Porcelite

Enterprises, Inc.

City Porcelain Refinishing Co. Inc.

Porcelain Repalr Company, Inc.

New Life Electro Glaze Process

Regal House (Bathnasters Int 1.)

Uni-Tub Co.

ACME Porcelain

Resurfacing Co.

JEvCo Co.

Thermo Bond, Inc.

New Gloss, Inc.

Dura Glaze Porcelain Refinishing Service

Perma-Brite of Northern Illinois, Inc.

Ark Porcelain

Refinishers

Lectro Glaze

of Chicago

K.R.T. Porcelain

Refinishing

Active Porcelain Refinishing

Custom Coating

California Bathtub Refinishing

J.C. Blending Serv.

V.C.S. Vinyl

Repair

Permaceram of South CaliEornia

Valley Porcelain Refinishing

Seisinore's Fiberglass

Cerma Glaze

ACIE Perfect Patch Co.

RM Batlitub Refinishing

Bathtubs and Sinks

Refinishing, Inc

Dokan Pierri

Kott Koatings

Gnu-Services Corp.
Tubs, Commodes, sinks

Tubs, sinks

Tubs only

Tubs, some sinks

Tubs, sinks

Tubs, sinks

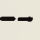

bs only

Tubs, sinks, commodes outside

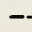

Tubs, sinks, commodes

Tubs

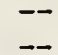

Tubs only

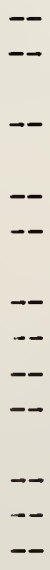

A.S.S.2/ Polyurethane

225

A.S.S. Polyurethane

A.S.S. Polyurethane

175

A.S.S. Epoxy urethane 200

A.S.S.

Ester

175

A.S.S. Phenollc

250

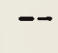

$-$

$--$

A.S.S.

Acld, solvent

A.S.S.

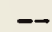

215

Epoxy

175

$-$

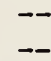

A.S.S.

Polyurethane

200

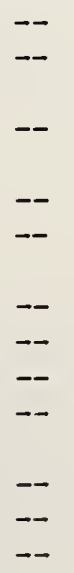

1/ The information presented in this table was provided by the restoration companies.

2/ A.S.S. = Acid, solvent, sand.

$3 /$ Cost of refinishing one bathtub 

APPENDIX B. INTERIM PERFORMANCE CRITERIA FOR RESTORATION COATINGS FOR PORCELAIN ENAMEL SURFACES

\section{B.1 INTRODUCTION}

These interim performance criteria are based upon the results of laboratory tests conducted on five restoration coatings and on specimens of unrestored porcelain enanel test panels. The tests and criteria are intended to be used in evaluating the performance of restoration coatings and they may be more severe than in-service situations. The criteria selected were chosen to reflect perfurmance characteristics which these materials would be expected to show inservice; they include appearance, adhesion, impact resistance, stain resistance, and fungal resistance. Abrasion resistance is included as part of the cyclic exposure test.

The key to the development of performance criteria was exposure of the panels to accelerated bathtub exposure cycling (ABEC) which includes wet and dry cycling, elevated water temperatures and surface abrasion. An automatic dishwasher was modified for continuous cycling using water temperatures of $43^{\circ} \mathrm{C}\left(110^{\circ} \mathrm{F}\right)$, air drying temperatures of $77^{\circ} \mathrm{C}\left(170^{\circ} \mathrm{F}\right)$ and detergent injection at each bath cycle. At the end of 28 bath cycles ( 24 hours), the cooled panels were abraded on a P.E.I. abrasion tester for 56 machine counts where the abrasive used is feldspar-containing cleanser (modified ASTM C 448 test) before repeating the cycle. Thus, one accelerated bathtub exposure cycle (ABEC) included 28 bath cycles and one abrasion cycle.

\section{B.2 PERFORMANCE CRITERIA}

\section{B.2.1 Appearance}

\section{Requirement}

When applied at the restoration coating company's designated rate and method, the restoration coating shall provide a smooth, uniform gloss appearance under ordinary conditions of illumination and viewing, both initially and after in-service exposure.

\section{Criterion}

When applied to a porcelain enamel test panel using the designated rate and inethod, the initial (before exposure) $60^{\circ}$ gloss measurements shall be 75 or greater as described in ASTM D 523. The initial apparent reflectivity (white only) [Directional Reflectance, $45^{\circ}, 0^{\circ}$ ] shall be at least 85 as described in ASTM $D$ 2244. After exposure to $25 \mathrm{ABECs}$, the $60^{\circ}$ gloss in the unabraded area shall be 70 or greater, and the color difference ( E) shall be less than two NBS units (ASTM D 2244).

\section{Commentary}

Materials for the restoration of porcelain enamel substrates should have initial gloss and reflectance characteristics similar to those of porcelain enamel. 
After exposure to accelerated bathtub exposure cycling, the restoration coatings should retain both color and gloss.

\section{B.2.2 Adhesion}

Requirement

The restoration coating shall adhere to a porcelaln enamel substrate both initially and after in-service exposure.

\section{Criterion}

The restoration coating shall have a stress at rupture value of at least $3.1 \mathrm{MPa}$ ( $450 \mathrm{psi}$ ) before exposure, and of at least $1.4 \mathrm{MPa}$ (200 psi) after exposure to 25 ABECs when the adhesion is measured by a pull-off technique, as described in section 4.2 .2 of this report.

\section{Commentary}

The degree to which restoration coatings adhere to porcelaln enamel substrates is very important, especially after exposure to in-use conditions such as wet and dry cycling, elevated water temperatures and abrasion.

\section{B.2.3 Impact Resistance}

\section{$\underline{\text { Requirement }}$}

The restoration coating shall have an impact resistance equal to or greater than that of the porcelain enamel substrate.

\section{Criterion}

The restoration coating shall have an impact resistance of at least $0.53 \mathrm{Nm}$ ( 4.7 in pounds) after exposure to $25 \mathrm{ABECs}$, when using a modified ASTM D 2794 procedure with a one pound aluminum cylinder.

Commentary

The minimum impact resistance of $0.53 \mathrm{Nm}$ stated above is the mean value obtained during testing of unrestored porcelain enamel test panels. All of the restoration coatings had impact resistance values higher than that of the unrestored porcelain because they were elastomeric.

\section{B.2.4 Stain Resistance}

\section{$\underline{\text { Requirement }}$}

The restoration coatings shall be resistant to household stains common to bathroom areas. 


\section{Criterion}

When Tintex, black hair dye, black shoe polish and lipstick are applied for a 16 hour period to restoration coating panels which had been exposed for 25 ABF.Cs, only a very light stain residue shall remain after scrubbing gently with warm soapy water (modified ASTM D 1308).

\section{Commentary}

These staining materials are among those which would likely be used in a bathroom area. In order to maintain an attractive appearance, the restoration coating should be easily cleaned if staining materials are spilled on the coating's surface.

\section{B.2.5 Fungal Resistance}

\section{Requirement}

The restoration finishes shall be resistant to fungal attack when exposed to in-use conditions.

\section{Criterion}

No fungus growth shall appear on the restoration finish after the 30 day exposure to the conditions of test method ASTM D 3273 (i.e., a rating of 10 according to ASTM D 3274).

Commentary

It is important that an organic coating used in warm, moist environments be resistant to fungal growth. 
BIBLIOGRAPHIC DATA

SHEET (See in structions)

1. PUBLICATION OR REPORT NO.

NBSIR $82-2553$
2. Performing Organ. Report Noof 3. Publication Date

July 1982

4. TITLE AND SUBTITLE

Development of Interim Performance Criteria for Restoration Coatings for Porcelain Enamel Surfaces

5. $\operatorname{AUTHOR}(\mathrm{S})$

James F. Seiler and Paul G. Campbell

6. PERFORMING ORGANIZATION (If joint or other than NBS, see instructions)

NATIONAL BUREAU OF STANDARDS

DEPARTMENT OF COMMERCE

WASHINGTON, D.C. 20234

9. SPONSORING ORGANIZATION NAME AND COMPLETE ADDRESS (Street, City, State, ZIP)

Department of Housing and Urban Development

Washington, DC

10. SUPPLEMENTARY NOTES

[ Document describes a computer program; SF-185, FIPS Software Summary, is attached.

11. ABSTRACT (A 200-word or less factual summary of most significant information. If document includes a significant bibliography or literature survey, mention it here)

A study was performed to develop interim performance criteria for restoration coatings for porcelain enamel surfaces. The laboratory study consisted of evaluating five restoration coatings which had been applied to porcelain enamel test panels with various surface conditions. Performance characteristics of the coatings examined included appearance, adhesion, impact resistance, stain resistance and fungal resistance. Existing test methods were used in the study if appropriate methods were available. However, the laboratory studies led to the development of a new cyclic exposure test and the use of a newly developed method for measuring adhesion. Adhesion of the coatings was the performance characteristic most sensitive to change with time of exposure to the newly developed cyclic exposure test. Interim performance criteria for restoration coatings for porcelain enamel surfaces were developed, based upon the results of the laboratory study.

Additional studies are being conducted to assess the performance and durability of selected restoration coatings applied to bath tubs in public housing units. Since the field studies are not yet completed, they are not addressed in this report.

12. KEY WORDS (Six to twelve entries; alphabetical order; capitalize only proper names: and separate key words by semicolons) Accelerated bathtub exposure cycle; performance criteria for restoration coatings; porcelain enamel restoration; restoration coatings

13. AVAILABILITY

X] Unlimited

For Official Distribution. Do Not Release to NTIS

Order From Superintendent of Documents, U.S. Government Printing Office, Washington, D.C. 20402.

[X] Order From National Technical Information Service (NTIS), Springfield, VA. 2216I
14. NO. OF

PRINTED PAGES

\section{6}

15. Price

$\$ 9.00$ 
